$$
\text { LA-SUB }--95-34
$$

Senior Research Project

at

San Jose State University

\title{
Investigation of the Electronic Properties and Morphology of Conducting Polymer Electrodes For Engineering Applications
}

Juan Landeros Jr.

Materials Engineering Department, San Jose State University

$$
\begin{gathered}
\text { Professor Patrick Pizzo } \\
\text { and }
\end{gathered}
$$

Professor Manfred Cantow

Materials Engineering Department, San Jose State University

Dr. Francisco Uribe

MEE-11 Electronic Research Group, Los Alamos National Laboratory

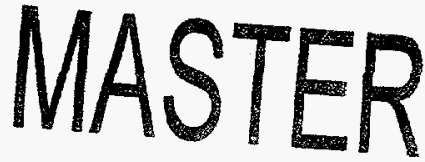

DISTRIBUTION OF THIS DOCUMENT IS UNUMTED

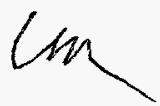




\section{DISCLAIMER}

This report was prepared as an account of work sponsored by an agency of the United States Government. Neither the United States Government nor any agency thereof, nor any of their employees, make any warranty, express or implied, or assumes any legal liability or responsibitity for the accuracy, completeness, or usefulness of any information, apparatus, product, or process disclosed, or represents that its use would not infringe privately owned rights. Reference herein to any specific commercial product, process, or service by trade name, trademark, manufacturer, or otherwise does not necessarily constitute or imply its endorsement, recommendation, or favoring by the United States Government or any agency thereof. The views and opinions of authors expressed herein do not necessarily state or reflect those of the United States Government or any agency thereof. 


\section{DISCLAMMER}

Portions of this document may be illegible in electronic image products. Images are produced from the best available original document. 


\section{Abstract}

In this project experiments were conducted to evaluate the performance of the conducting polymer polyaniline (PAni) and poly-3-(4-fluorophenyl)-thiophene (PFPT) as the active material in electrochemical capacitors. Using scanning electron microscopy and cyclic voltammetry, the morphology and charge/discharge characteristics of the as-grown polymers were studied under different electrochemical conditions. When electropolymerized at high current densities in aqueous acid solution, PAni exhibits a morphology consisting of a network of interwoven fibrils. It was shown that layers of this PAni network can be electropolymerized onto a thin-planar metal substrate resulting in a decrease in cathodic and anodic peak separations, improving charge/discharge reversibility. A continuous PAni network will make possible a decreases in the total weight of the electrodes with respect to those electrodes grown onto a fibrous carbon substrate of high surface area and high porosity. The effect of different growth electrolytes on the charge/discharge process was also characterized. Hydrochloric acid electrolyte provided an optimum polymer deposition, with respect to morphology and capacitive performance.

PFPT films were grown from a solution in a non-aqueous solution. High growth current densities affected the performance of PFPT polymer films in a positive manner. A growth rate of $20 \mathrm{~mA} / \mathrm{cm}^{2}$ not only provided an increase in charge storage, but in the amount of polymer deposited when compared to equivalent amounts deposited at $1 \mathrm{~mA} / \mathrm{cm}^{2}$. The morphology of the deposited conducting polymer is shown to be one of the most important characteristics in the attempt to achieve an ideal electrochemical capacitor electrode. The polymer morphology directly affects the charge/discharge process because of the strong interaction between ionic conductivity in the electrolyte and the electronic conductivity of the polymer. Cyclic-dependent degradation of the PFPT films was observed. Further research is required to define the controlling mechanism(s) of electrolyte/electrode degradation. 


\section{Acknowledgments}

I would like to thank Francisco Uribe, Shimshon Gottesfield, and Andy Rudge at Los Alamos National Laboratories, and Professors P. Pizzo, M. Cantow, and K.S. Harsha of the Materials Engineering

Departmant at SJSU for their assistance. Further gratitude to Dr. Michael Thomas at National Semiconductor for the donated glove box, and John Hamilton at Vacuum Atmospheres Company for his time and involvement in the set-up of the glove box. 


\section{Table of Contents}

Abstract i

Acknowledgements ii

Table of Contents iii

Table and Figure Captions iv

Introduction 1

Candidate Conducting Polymers 5

$\begin{array}{ll}\text { Charge Storage } & 10\end{array}$

$\begin{array}{ll}\text { Electrolytes } & 12\end{array}$

Conducting Polymer Growth 14

Conducting Polymer Testing: Cyclic Voltammetry 16

Objective \& Hypothesis $\quad 18$

Experimental Methods $\quad 19$

Results and Discussion $\quad 24$

Polyaniline $\quad 24$

Effect of growth current density $\quad 24$

$\begin{array}{ll}\text { Effect of acid electrolyte } & 27\end{array}$

Effect of planar substrate $\quad 30$

Poly-3-(4-fluorophenyl)-thiophene $\quad 31$

Deposition $\quad 32$

Effect of growth current density $\quad 39$

PFPT Morphology $\quad 40$

Effect of growth electrolyte concentration 44

Cycle dependent PFPT degradation $\quad 46$

Conclusions $\quad 51$

Future Directions $\quad 52$

References $\quad 53$ 


\section{Table and Figure Captions}

Table 1. Classifications of materials based on resistivity

Fig. 1. Schematic representing the manner in which charge

separation and/or energy storage occur in (a) electrochemical capacitors, (b) conventional batteries, and (c) conventional capacitors.

Fig. 2. Specific energy vs. specific power plot, depicting

performance regions of conventional capacitors, batteries, and electrochemical capacitors [1].

Fig. 3. The conducting polymers (a) PAni and (b) PFPT. 6

Fig. 4. The $\pi$-electron band structure of a polymer. 6

Fig. 5. The formation of $\pi$-bonds by the overlap of p-orbitals. 7

Fig. 6. Band structure evolution of polythiophene derivatives on 9 doping [15]: (a) undoped, (b) $0.01 \%$ doping level with polaron states in the gap, (c) few \% doping level, bipolaron states appear, (d) $30 \%$ doping level, bipolaron states overlap and form two bands, and (e) hypothetical $100 \%$ doping level.

Fig. 7. Temperature dependence of the conductivity of PMeT $\left(\mathrm{ClO}_{4}^{-}\right)$0.20 [16].

Fig. 8. A schematic representation of the charging and discharging processes associated with conducting polymers in an electrolyte.

Fig. 9. Chemical structure of tetramethyl ammonium cation, (a), and trifluoromethane sulfonate anion, (b).

Fig. 10. Cell assembly for growing and testing of single electrodes. 14

Fig. 11. Scanning electron micrographs, viewed from the top 15 surface, of carbon substrate.

Fig. 12. Polymer growth on a carbon fiber, cross-sectional view.

The carbon fiber is the white area and the polymer is grown in a sheath around and along it.

Fig. 13. An example of a typical cyclic-voltammogram, current vs. voltage. 
Fig. 14. Primary components of an electrochemical laboratory which were used throughout this research. The equipment pictured include: (a) Vacuum Atmosphere Company glove box, (b) EG\&G Model 273 Potentiostat/Galvanostat, (c) IBM computer, and (d) EG\&G Model 5210 Lock-In Amplifier.

Fig. 15. Laboratory supplies and equipment found inside the glove box, included are: chemical containers, growth cells, electrodes, waste containers (solid/chemical), scales, clamps and posts, syringes, and electric feedthroughs.

Fig. 16. Procedure for carbon electrode preparation.

Fig. 17. Ag/Ag+ reference electrode assembly.

Fig. 18. Electrochemical polymerization reaction of polyaniline

from its monomer constituent.

Fig. 19. Scanning electron micrographs of PAni growth at different current densities, on carbon substrates, viewed from the top surface. Effects of growth densities of $100 \mu \mathrm{A} / \mathrm{cm}^{2}$ for 100000 s (a) and $10 \mathrm{~mA} / \mathrm{cm}^{2}$ for 1000 s (b) are illustrated.

Fig. 20. Effect of current density on cyclic voltammetry performance. PAni growth on carbon paper from a solution of $0.5 \mathrm{M}$ aniline in $1 \mathrm{M} \mathrm{HCl}(\mathrm{aq})$.

Fig. 21. Effect of growth acid electrolytes on C-V performance. Acid electrolytes tested: $0.5 \mathrm{M}$ Camphorsulfonic acid, $1 \mathrm{M} \mathrm{HClO}_{4}$, and $1 \mathrm{M} \mathrm{H2SO} 4$ containing $0.5 \mathrm{M}$ aniline.

Fig. 22. Effect of acid electrolytes on PAni morphology, top surface views. PAni grown at $10 \mathrm{~mA}$ for $1000 \mathrm{~s}$ in $0.5 \mathrm{M}$ aniline in (a) $0.5 \mathrm{M}$ camphorsulfonic acid, (b) $1 \mathrm{M} \mathrm{H}_{2} \mathrm{SO}_{4}$, and (c) $1 \mathrm{M} \mathrm{HClO}_{4}$. Fig. 23. Effect of a platinum planar substrate on (a) the cyclic voltammetry performance and (b) the morphology of electrochemically grown polyaniline, grown at $10 \mathrm{~mA}$ for 1000 s out of $0.5 \mathrm{M}$ aniline in $1 \mathrm{M} \mathrm{HCl}(\mathrm{aq})$. The scanning electron photomicrograph shows a top surface view at a slight angle.

Fig. 24. PFPT deposition onto porous carbon substrate at 20 $\mathrm{mA} / \mathrm{cm}^{2}$ from a solution of $0.1 \mathrm{M}$ TMAT in acetonitrile. Fig. 25. PFPT deposition onto porous carbon substrate at 1 $\mathrm{mA} / \mathrm{cm}^{2}$ from a solution of $0.1 \mathrm{M}$ TMAT in acetonitrile. 
Fig. 26. Initial stages of PFPT Deposition onto carbon substrate at

$20 \mathrm{~mA} / \mathrm{cm}^{2}$ for 5 seconds[face view].

Fig. 27. Discontinuous PFPT layer on carbon fibers at $20 \mathrm{~mA} / \mathrm{cm}^{2}$

for 100 seconds[face view].

Fig. 28. Cross-section of carbon electrode after polymer deposition at $20 \mathrm{~mA} / \mathrm{cm}^{2}$ for $1000 \mathrm{~s}$ in $0.1 \mathrm{M}$ FPT in $1 \mathrm{M}$ TMAT in acetonitrile. Fig. 29. Cross-section of carbon electrode after polymer deposition 36 at $1 \mathrm{~mA} / \mathrm{cm}^{2}$ for $20000 \mathrm{~s}$ in $0.1 \mathrm{M}$ FPT in $1 \mathrm{M}$ TMAT in acetonitrile. Fig. 30. Cross-section of carbon electrode after polymer deposition at $20 \mathrm{~mA} / \mathrm{cm}^{2}$ for $1000 \mathrm{~s}$ in $0.1 \mathrm{M}$ FPT in $1 \mathrm{M}$ TMAT in acetonitrile Fig. 31. Cross-section of carbon electrode fiber after polymer deposition at (a) $20 \mathrm{~mA} / \mathrm{cm}^{2}$ for 1000 s and (b) $1 \mathrm{~mA} / \mathrm{cm}^{2}$ for $20000 \mathrm{~s}$ in $0.1 \mathrm{M}$ FPT in $1 \mathrm{M}$ TMAT in acetonitrile.

Fig. 32. Effect of growth current density on cyclic voltammetry of electro-deposited PFPT from a solution of $0.1 \mathrm{M}$ FPT in $1 \mathrm{M}$ TMAT in acetonitrile with equivalent growth charge, $4 \mathrm{C}$. Sweep rate $=25 \mathrm{mV} / \mathrm{s}, x$-axis $=0.5 \mathrm{~V} / \mathrm{inch}, \mathrm{y}$-axis $=20 \mathrm{~mA} / \mathrm{inch}$.

Fig. 33. Surface view of carbon electrode after polymer deposition 40 at $20 \mathrm{~mA} / \mathrm{cm}^{2}$ for $200 \mathrm{~s}$ in $0.1 \mathrm{M}$ FPT in $1 \mathrm{M}$ TMAT in acetonitrile. Fig. 34. Surface view of carbon electrode after polymer deposition at $10 \mathrm{~mA} / \mathrm{cm}^{2}$ for $400 \mathrm{~s}$ in $0.1 \mathrm{M}$ FPT in $1 \mathrm{M}$ TMAT in acetonitrile. Fig. 35. Surface view of carbon electrode after polymer deposition at $1 \mathrm{~mA} / \mathrm{cm}^{2}$ for $4000 \mathrm{~s}$ in $0.1 \mathrm{M}$ FPT in $1 \mathrm{M}$ TMAT in acetonitrile. Fig. 36. Surface view of carbon electrode after polymer deposition at $10 \mathrm{~mA} / \mathrm{cm}^{2}$ for $400 \mathrm{~s}$ in $0.1 \mathrm{M}$ FPT in $1 \mathrm{M}$ TMAT in acetonitrile. Fig. 37. Surface view of carbon electrode after polymer deposition at $20 \mathrm{~mA} / \mathrm{cm}^{2}$ for $1000 \mathrm{~s}$ in $0.1 \mathrm{M}$ FPT in $1 \mathrm{M}$ TMAT in acetonitrile. Fig. 38. Surface view of carbon electrode after polymer deposition at $1 \mathrm{~mA} / \mathrm{cm}^{2}$ for $20000 \mathrm{~s}$ in $0.1 \mathrm{M}$ FPT in $1 \mathrm{M}$ TMAT in acetonitrile. Fig. 39. Effect of growth electrolyte concentration on cyclic voltammetry.

Fig. 40. Surface view of carbon electrode after polymer deposition at $10 \mathrm{~mA} / \mathrm{cm}^{2}$ for $400 \mathrm{~s}$ in 0.1 M FPT in 0.1 M TMAT in acetonitrile. 
Fig. 41. Surface view of carbon electrode after polymer deposition at $1 \mathrm{~mA} / \mathrm{cm}^{2}$ for $4000 \mathrm{~s}$ in $0.1 \mathrm{M}$ FPT in 0.1 M TMAT in acetonitrile.

Fig. 42. Effect of degradation on cyclic voltammetry.

Fig. 43. Cyclic voltammogram of bare electrodes in 1 M TMAT in acetonitrile.

Fig. 44. Surface view of carbon electrode after polymer deposition (and cycled) at $10 \mathrm{~mA} / \mathrm{cm}^{2}$ for 2000s in $0.1 \mathrm{M}$ FPT in $1 \mathrm{M}$ TMAT in acetonitrile.

Fig. 45. Optical photomicrograph of surface view of carbon electrode after polymer deposition (and cycled) at $10 \mathrm{~mA} / \mathrm{cm}^{2}$ for $2000 \mathrm{~s}$ in 0.1 M FPT in $1 \mathrm{M}$ TMAT in acetonitrile. 


\section{Introduction}

Electrochemical capacitors are high power and high energy storage devices. Energy density from $1-10 \mathrm{~W} \cdot \mathrm{h} / \mathrm{Kg}$, and power densities greater than $500 \mathrm{~W} / \mathrm{Kg}$ are not uncommon [1]. Energy density represents the energy per unit weight associated with a given capacitor and units are often reported as joules per gram or watt hour per gram. The energy is determined by eq. 1 , where $\mathrm{E}=$ energy, $\mathrm{C}=$ capacitance, and $\mathrm{V}=$ voltage:

$$
E=1 / 2 C V^{2}
$$

Power density is the rate of doing work per unit gram and units are often given as watts (or foot pounds per second) per gram.

Unlike conventional batteries, electrochemical capacitors do not rely on the storage of chemical energy in the form of reactants. Electrochemical capacitors differ from conventional capacitors in that conventional capacitors utilize the storage of electrostatic energy when an electric field is applied across a dielectric. The charge separation, and thus the energy storage, of electrochemical capacitors relies on the interaction of a metallic electrode and an ionically conducting electrolyte when an electrochemical potential is applied. Figure 1(a) schematically presents the charging and discharging of electrochemical capacitors. Figure 1(b) presents one cell of a lead acid storage battery and the chemical reaction that drives it. Figure 1(c) shows a schematic of a conventional capacitor.

In Figure 1(a), the metallic electrode is shown connected to the cathode of an external circuit. As electrons are added to the electrode a negative charge builds. An electrostatic attraction attaches cations to the surface of the electrode. This is described as the charging of the electrode. It is the double layer of charge that forms at the interface which provides energy storage. 
(a)

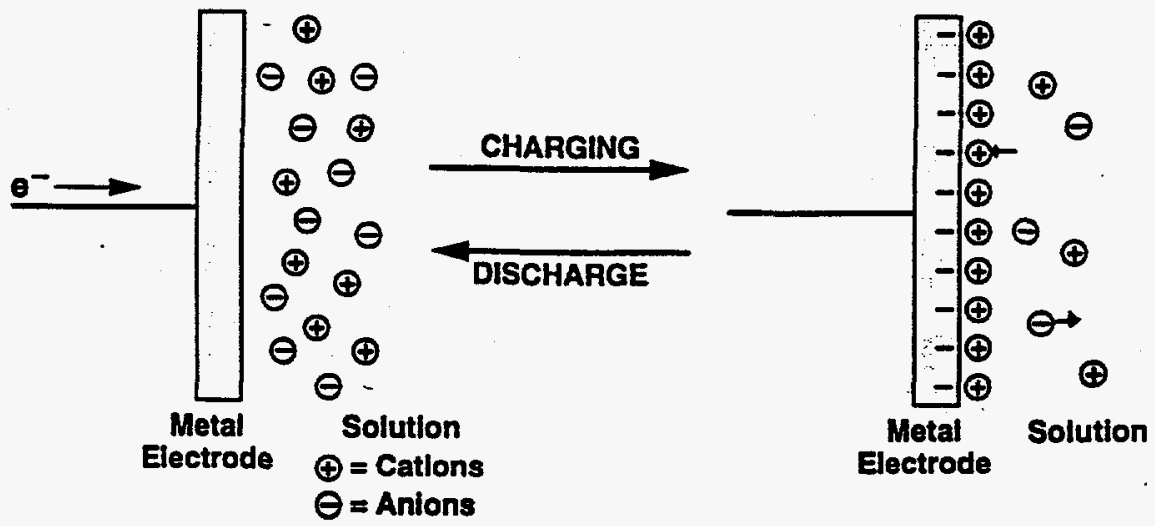

(b)

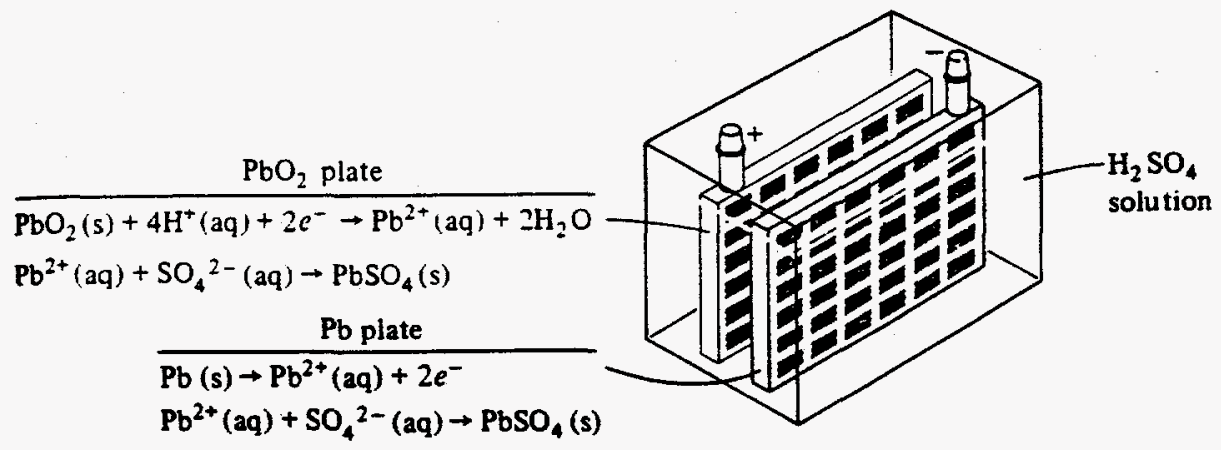

(c)

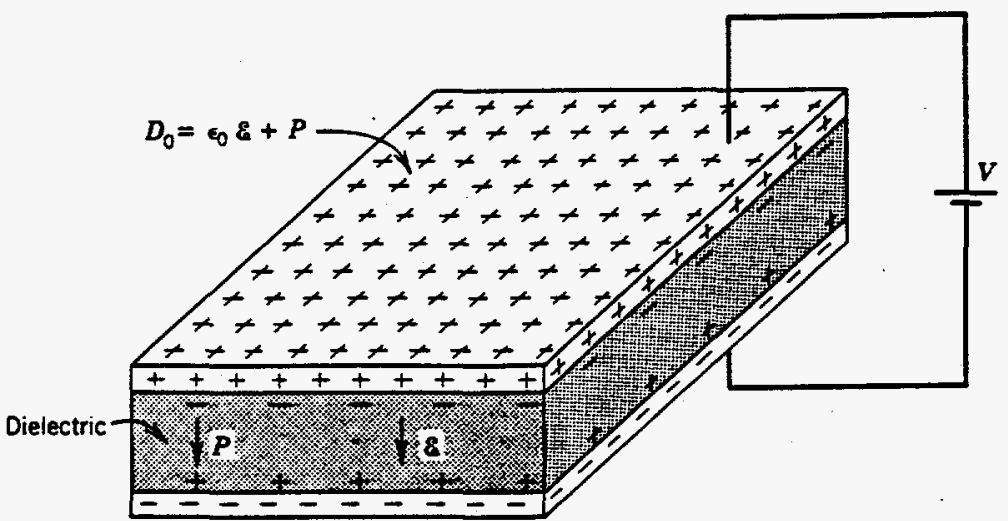

Fig. 1. Schematic representing the manner in which charge separation and/or energy storage occur in (a) electrochemical capacitors, (b) conventional batteries, and (c) conventional capacitors. 
Figure 2 is a plot of energy density vs. power density for common energy storage devices: conventional capacitors, electrochemical capacitors, and conventional batteries. Conventional capacitors fall in the regime of high power density but low energy density, while conventional batteries provide high energy density at low power density. The use of novel materials as the active component in electrochemical capacitors may provide intermediate values of energy density and power density, and thus have the intrinsic ability to bridge this gap in performance. As expectations have risen on potential performance levels, so have potential applications.

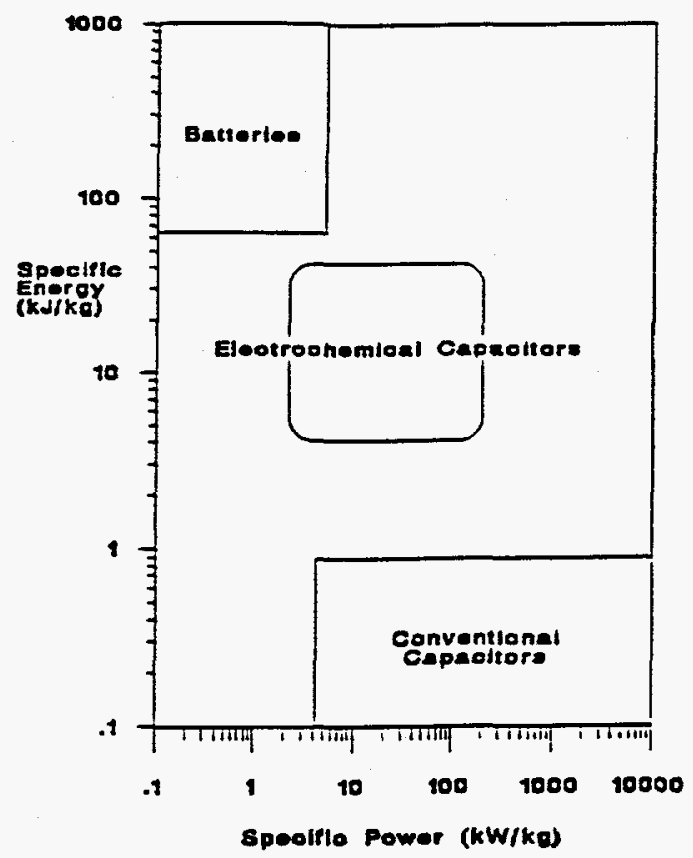

Fig. 2. Specific energy vs. specific power plot, depicting performance regions of conventional capacitors, batteries, and electrochemical capacitors [1].

A typical application for electrochemical battery is the electric motor vehicle. A well documented problem with electric vehicles is the effect of basing an electric vehicles' power solely on batteries. To achieve the automobile performance levels expected from the consumer, large and heavy batteries are required. The GM Impact 
prototype, for example, has a curb weight of $2910 \mathrm{lbs}$., and $1100 \mathrm{lbs}$. are accounted for by its twenty-seven, 12-volt batteries [3]. The efficiency of such 'heavy' vehicles suffers greatly. The average vehicle would require recharging every 100 miles. Therefore, a primary goal in the automotive community is to develop lighter vehicles without sacrificing passenger safety, handling, acceleration, and design. The battery is expected to be complemented by the presence of electrochemical capacitors. Not only will these capacitors aid in power output, but high energy densities will result in smaller battery requirements.

Any car manufacturer wishing to sell vehicles in the state of California from 1998 onward is required to meet a new California law which mandates that at least $2 \%$ of the vehicles sold by a manufacturer produce zero emissions [17]. The percentage of vehicles with zero emissions goes up to $10 \%$ by 2010 . Car manufacturers are now spending large amounts of research dollars on the development of a new age of vehicles which meet this stringent emissions requirement: electric vehicles. As a result, recent interest in the use of electrochemical capacitors in such applications as reserve power supplies for electric vehicles has developed [2]. Use of these capacitors in parallel with electric vehicle car batteries will significantly improve performance during acceleration and hill climbing, areas where energy is required at high rates. The electrochemical capacitor's ability to supply a charge at a high rate and recharge during constant speed traveling and deceleration, either from the battery or by regenerative braking, presents additional characteristics that have been long desired.

The potential applications are exciting, yet the performance requirements are stringent. It is the purpose of this research effort to investigate the performance characteristics of candidate conducting polymers as the active material in electrochemical capacitors. The optimization of polymer deposition processes is essential to the overall success of this device. The emphasis of this project is to establish a deposition criteria where a morphology may be acquired which optimizes electrochemical performance. 


\section{Candidate Conducting Polymers}

The electrode in most electrochemical capacitors is a metal. The electrolyte, which will be discussed in greater detail in later sections, is most commonly an aqueous solution. The basis for energy storage and charge separation in an electrochemical capacitor is the interaction between the electrolyte and the electrode. Conducting polymers present an exciting alternative as the active component of the cell. Conducting polymers can be doped and undoped rapidly to high charge densities (approximately 500 $\mathrm{C} / \mathrm{g}$ for polyaniline). They thus have the potential as a low cost, low density alternative electrode material [1]. The following two conducting polymers are prime candidates for use in electrochemical capacitors: polyaniline (PAni) and poly-3-(4-fluorophenyl)thiophene (PFPT). These polymers have potential application because of a good balance between resistivity (low), charge capacity (high), and durability. For example, polyaniline has an electrical resistivity of $10^{1}-10^{-2} \Omega \mathrm{cm}$ [13]. Typical polymers (for example, polyethylene and Teflon) have electrical resistivity on the order of $10^{16} \Omega \mathrm{cm}$ and are thus insulators. Table 1 shows the classifications of materials based on resistivity.

Table 1. Classifications of materials based on resistivity.

\begin{tabular}{|c|c|}
\hline Resistivity, $\Omega \mathrm{cm}$ & Class \\
\hline $0-10^{3}$ & conductor \\
\hline $10^{3}-10^{7}$ & semiconductor \\
\hline $10^{15}$ and higher & insulator \\
\hline
\end{tabular}


The PAni and PFPT molecular structures are schematically presented in Fig. 3. The PFPT conducting polymer has a polythiophene backbone with flourophenyl side groups. This novel polymer was synthesized at Los Alamos National Laboratories by MEE-11, an electronics materials and device research group which is sponsoring this research. PFPT is one focus of this study.

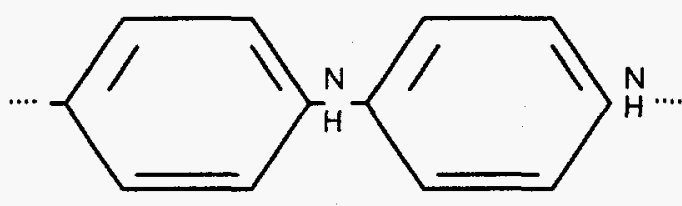

(a)

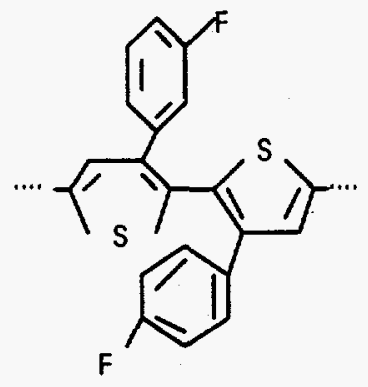

(b)

Fig. 3. The conducting polymers (a) PAni and (b) PFPT.

The important electronic structural concepts for a conducting polymer are electron affinity, band gap, ionization potential, and band width [12]. Figure 4 shows the $\pi$ electron band structure of an ideal polymer. The energy required to remove an electron from along the polymer chain into vacuum is known as the ionization potential, IP. A polymer which is easily oxidized will have a small IP value. The electron

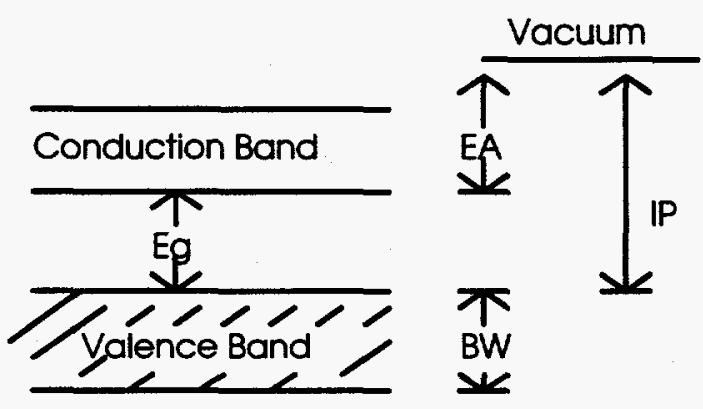

Fig. 4. The $\pi$-electron band structure of a polymer. 
affinity, EA, describes the ease in which electrons are added to the polymer and anions are formed. A polymer which is easily reduced will have a large EA value. The optical band gap, Eg, is the difference between the IP and the EA. The band width, BW, describes the size of the highest occupied band of states with $\pi$-electron character. $\pi$ electrons is a reference to the covalent bond formed by the sideways overlap of atomic orbitals. For example, the carbon-carbon double bonds contain a $\pi$-bond formed by the sideways overlap of two p-orbitals, as shown in Figure 5 . The conjugated $\pi$-electron backbone, in general, has a low energy band gap, low ionization potential, and high electron affinity. If $\pi$-electrons are highly interactive, this suggest a high intra-chain mobility, resulting in high electrical conductivity.

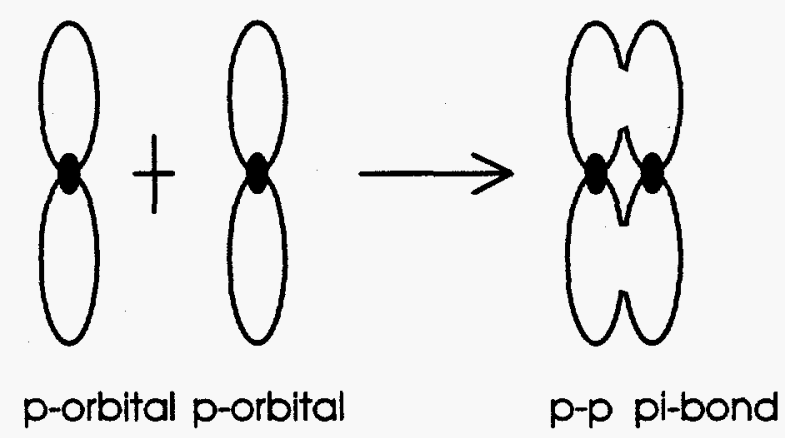

Fig. 5. The formation of $\pi$-bonds by the overlap of $p$-orbitals.

In conducting polymers, the $\pi$ energy levels become delocalized through conjugation to form an energy band - the valence band - which is completely full of electrons when the polymer is in its undoped state. The same happens to the excited state $\pi^{*}$ energy levels and another energy band is formed: the conduction band which is completely empty of electrons when the polymer is in its undoped state. Because there are no vacant energy states in the valence band and no filled energy states in the conduction band, the polymer does not conduct in the undoped state (analogous to an intrinsic semiconductor, e.g. titanium dioxide) at absolute zero. When the polymer is oxidized (i.e. 
p-doped), electrons are removed from the valence band leaving positive charge, holes, which are charge carriers. The result is a conducting polymer. When the polymer is reduced, electrons are injected into the conduction band and become charge carriers and so the polymer becomes conducting again, and this is known as n-doping. This is not the same as chemical doping whereby the polymer may be p-doped by adding an inorganic element, say iodine, which takes an electron to become iodide, and leaves positive charges along the polymer. Conversely sodium can be added to chemically $\mathrm{n}$-dope the polymer as the sodium atom gives an electron to the polymer to become a sodium cation, and thus make the polymer conducting. In the electrochemical experiments conducted during this research, an external applied voltage creates the electrons or holes that are necessary to change the electronic state of the polymer.

The electronic conductivity, $\sigma$, of any material is proportional to the product of the, electronic charge, $\mathbf{e}$, carrier mobility, $\mu$, and the free-carrier concentration, $\mathbf{n}$ and $\mathbf{p}$, as shown in eq (2):

$$
\sigma=\mathbf{n}|\mathbf{e}| \mu_{\mathbf{e}}+\mathbf{p}|\mathbf{e}| \mu_{\mathbf{h}}
$$

The conjugated carbon backbones of conducting polymers provide the high carrier mobility necessary for electrical conduction. In large band gap, conjugated polymers for example, the carrier concentration is low, and thus the conductivity is negligible. However, by doping these polymers, high conductivity is generated. The carrier concentration can directly be increased by creating a radical cation (or hole) on the polymer chain which aids in electronic conductivity (see eq. 2).

A second electronic structural model has been put forward to explain electrical conduction in conducting polymers. It has been suggested that the formation of polarons (a single charged paramagnetic state) and bipolarons (in polythiophene derivatives, for example) modify the band structure of polymers from insulator to conductor behavior $[14,15]$. Figure 6 shows the band structure evolution of polythiophene derivatives on doping according to Bredas et al. [15]. In the undoped state, the conduction band and 
valence band are separated by $2.2 \mathrm{eV}$. Optical data show the development of bands in the band gap, as illustrated in Fig. 6(b) through 6(e). The original band gap [Fig. 6(a)] increases from 2.2 to $2.9 \mathrm{eV}$ as the bipolaron states overlap (see Fig. 6d). At $100 \%$ doping the lower and upper bipolaron bands merge with the valence band and the conduction band, respectively. As a result, the band gap becomes $0.14 \mathrm{eV}$ (see Fig. 6e).

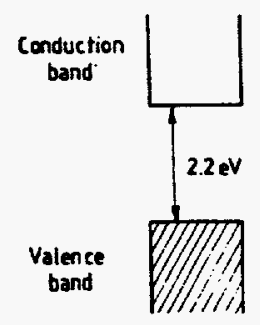

(a)

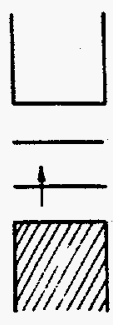

(b)

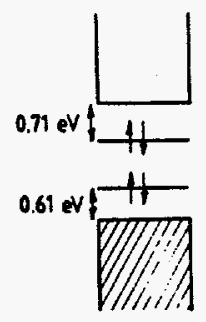

(c)

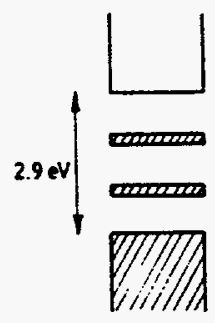

(d)

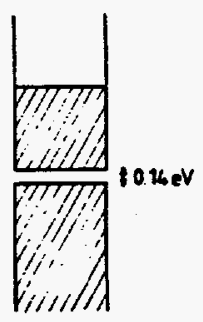

(e)

Fig. 6. Band structure evolution of polythiophene derivatives on doping [15]: (a) undoped, (b) $0.01 \%$ doping level with polaron states in the gap, (c) few \% doping level, bipolaron states appear, (d) $30 \%$ doping level, bipolaron states overlap and form two bands, and (e) hypothetical $100 \%$ doping level.

The conductivity reflected in the preceding polaron discussion is not consistent with the values acquired in the laboratory [14]. Differences in measured conductivity are believed to be attributed to impurities, monomer purity and electrode surface when electrochemical parameters are considered, and poor interfribrillar contact (a lack of crystalline structure which in turn affects electron mobility) [16]. Poor interfribrillar contact is predicted to have a large effect and is believed to be the cause of the variations of conductivity with temperature.

As Figure 7 shows, as temperature rises the conductivity increases [16]. This is the opposite of metallic compounds, but consistant with the semiconductor, band gap model. Electron mobility determines conduction in a metal. As temperature increases, atomic vibrations and interactions will scatter electrons resulting in a conductivity decrease. However, derivatives of polythiophene are more affected by a change in charge carrier concentration than by electron mobility. The charge carrier concentration is more 
dependent on the temperature than is electron mobility. Therefore, the temperature dependence of conductivity is dictated by the carrier concentration. This is similar to a semiconductor. It can therefore be said that the polaron model may be practical in understanding the development of a conducting polymer. It does not predict a transition to quasi-metallic behavior, i.e. conductivity decrease with increasing temperature. Fig. 7 shows that the converse behavior is observed.

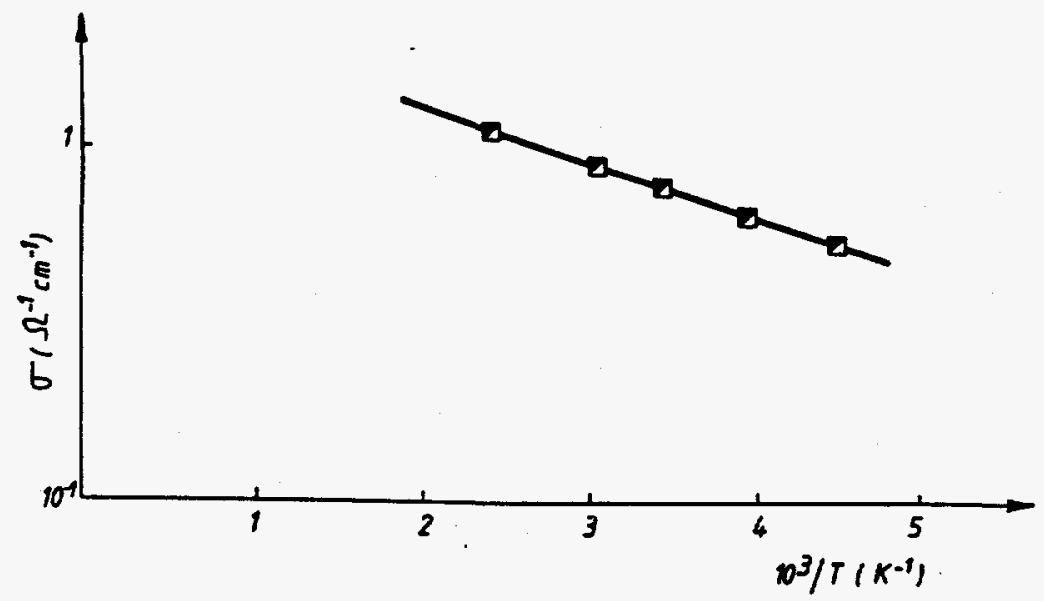

Fig. 7. Temperature dependence of the conductivity of $\mathrm{PMeT}\left(\mathrm{ClO}_{4}^{-}\right) 0.20[16]$.

\section{Charge Storage}

The conducting polymers being studied in this project have the intrinsic ability to conduct electrons along their backbones when charged in an electrolyte solution. As electrons are extracted from the polymer, a positive charge (a hole) results along the polymer [5]. In a given electrolyte, the anions will become electrostatically attracted to the polymer [8,9]. This state is known as p-doped (or oxidized). P-doping results because of the positively charged polymer molecular backbone. It is represented schematically in Figure 8. In this figure, the schematic on the left shows a conducting polymer attached to a metallic substrate, and the substrate connected to the anode of an external circuit. As a 
voltage is applied across the 'electrode' to a cathode, not shown, electrons are pulled off of the polymer backbone and flow into the external circuit. The circuit is electrically connected between electrodes via an electrolyte solution, depicted as the ionic solution in Figure 8.

The discharging of the stored energy is depicted by the p-dedoping when the process is reversed (Fig. $8 \mathrm{~b} \rightarrow$ Fig. 8a). Note that electrons have to be fed back to the collection plate in the external circuit in order for p-dedoping to occur. The resulting charge and discharging is the basis for electrochemical capacitor performance.

$\mathrm{N}$-doping is a term describing the charging process of a polymer in the opposite manner in which dedoping occurs. That is, electrons are fed into the conducting polymer upon attachment to an external cathode. Cations are then electrostatically attracted to the negatively charged polymer backbone.

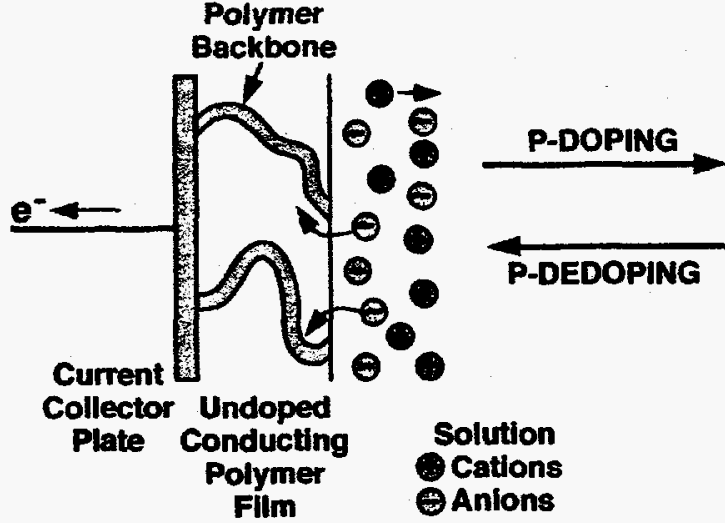

(a)

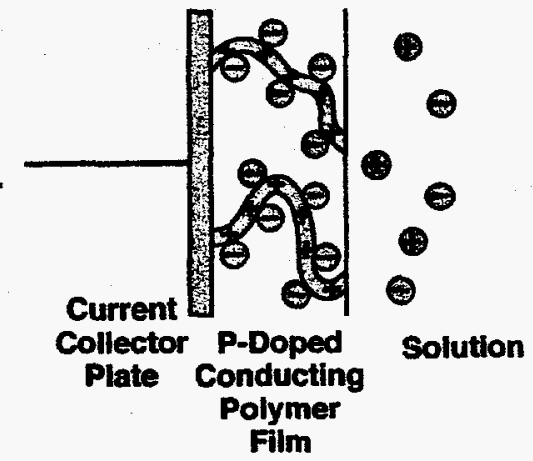

(b)

Fig. 8. A schematic representation of the charging and discharging processes associated with conducting polymers in an electrolyte.

The phenomenon of ion transport and electronic conductivity of the polymer are quite important in the electronic performance of the conducting polymer. The resistivity 
of the electrolyte may often dominate the electrical behavior of the electrochemical capacitor [9]. Further discussion of the electrolyte and its contribution to overall charge/discharge performance is discussed in the next section.

\section{Electrolytes}

The electrolytes in electrochemical capacitors play a major role in capacitive performance. As described previously, the electrolyte is the medium in which charge may be stored through ion attachment to the active material in the electrochemical capacitor (i.e. the conducting polymer). Therefore, it is vital that the electrolyte is optimized. The features that are used to characterize an electrolytes performance are cell voltages, conductivity of the electrolyte, and ion size and mobility.

The energy density of an electrochemical capacitor is given by equaiton 1: the density is directly proportional to the square of the voltage. Therefore, to acquire a high energy density it is desired that one have the highest obtainable cell voltage. However, power density is also dependent on the conductivity of the electrolyte. The solubility of the electrolyte becomes important as an increase in the concentration of ions in solution will result in an increase in ionic conductivity. Finally, the ion size is important as this will effect mobility and ionic penetration of the active material. As electrons from the polymer are injected or rejected by an external field, the ions are required to compensate for the charge imbalance through ion penetration. A smaller more mobile and more stable ion will benefit such a process.

Two types of electrolyte solution are utilized throughout this project: non-aqueous and aqueous. Dilute acids, such as hydrochloric and sulfuric acids in $\mathrm{H}_{2} \mathrm{O}$, are examples of the aqueous electrolytes employed. Aqueous electrolytes are advantageous because of their high conductivity, wide temperature range of stability, and low cost. However, voltage ranges are limited, $<1 \mathrm{~V}$, in such electrolytes because of polymer degradation 
(upon chemical reaction with the water component of the electrolyte) [1,2]. Much care is required because applying too large an over-voltage may result in toxic chemical reactions and subsequent gas evolution. This aspect of electrolyte durability is presented as a result and discussed in the section, Cycle Dependent PFPT Degredation.

The non-aqueous electrolytes employed are organic solvents. Because these electrolytes do not present the chemical reactivity of aqueous systems, voltages in the range of 3 to 4 volts may be reached. Such increases in voltage greatly enhance the amount of stored energy. However, these electrolyte systems are not as conductive as aqueous systems, resulting in power restrictions. Furthermore, work involving nonaqueous electrolytes requires an inert atmosphere (i.e. a glove box). A glove box is required because moisture and oxygen, even in minute amounts, may restrict the applied voltages through chemical degradation of the polymer [7].

Tetramethylammonium trifluoromethansulfonate in acetonitrile will be utilized as the non-aqueous electrolyte throughout this project. This electrolyte was developed at Los Alamos National Laboratories, New Mexico. It has a high solubility in acetonitrile, approximately 10 -times greater solubility than most organic electrolyte solvents. The cations share an important physical feature as well. They are relatively small and stable allowing for, higher mobility, easier penetration of the polymer and better $n$-doping. The active ions in this electrolyte are structurally presented in Figure 9. A $1 \mathrm{M}$ solution of this salt provides a conductivity of $\sigma=2.5 \times 10^{-2} \mathrm{~S} \mathrm{~cm}^{-1}$ (a corresponding resistivity of $\rho=$ $40 \Omega \mathrm{cm})$.<smiles>C[N+](C)(C)C</smiles>

(a)

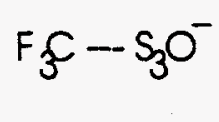

(b)

Fig. 9. Chemical structure of tetramethyl ammonium cation, (a), and trifluoromethane sulfonate anion, (b). 
As a general rule, the greater the ionic mobility in the electrolyte and the greater the concentration of participating members, the better the performance of the electrochemical capacitor.

\section{Conducting polymer growth}

The polymers throughout this project are prepared electrochemically from a solution containing the respective polymer 'mer' constituents. A constant oxidation current is utilized for the electrochemical deposition of the polymer onto a desired substrate $[2,6]$. The cell assembly for growing single conducting polymer electrodes is presented in Figure 10. The cell is a $20 \mathrm{ml}$ glass vial with a Teflon cap. The three electrodes in the cell are the reference electrode, counter electrode, and working electrode.

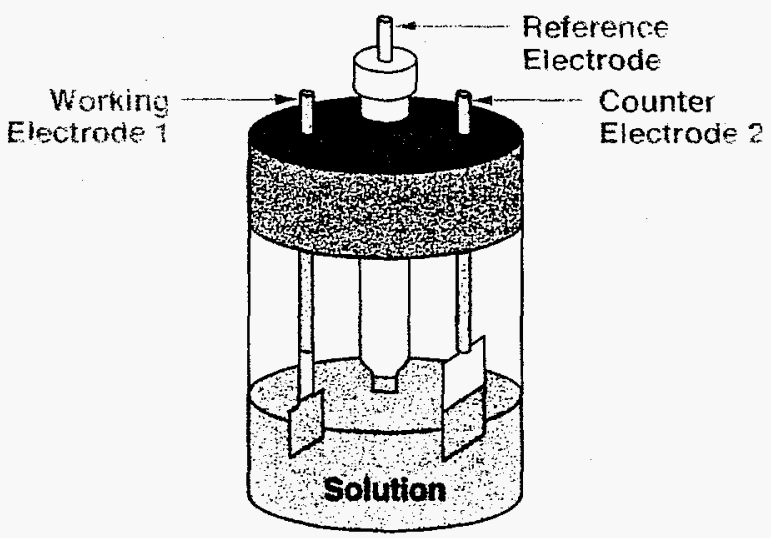

Fig. 10. Cell assembly for growing and testing of single electrodes. 
The reference electrode is a $\mathrm{Ag} / \mathrm{Ag}+$ reference electrode, and is utilized during cyclic voltammetry experiments as a voltage reference [4]. During deposition at constant current density it provides a measure of the voltage on the surface of the growing polymer, an important parameter in monitoring the overall growth morphology as will be seen in this investigation. The counter electrode consist of a platinum mesh, spot welded to a platinum wire. The working electrode consist of a carbon substrate. The carbon substrate consist of a network of carbon fibers, as seen in Figure 11. The carbon fibers present a large surface area for polymer deposition and a high porosity for electrolyte access. A conducting silver epoxy is used to attach the working electrode to the platinum wirc. Only the carbon substrate is immersed in the electrolyte of the electrochemical cell.

An example of the morphology of an electrochemically grown polymer on a single carbon fiber of the substrate is shown in Figurc 12.

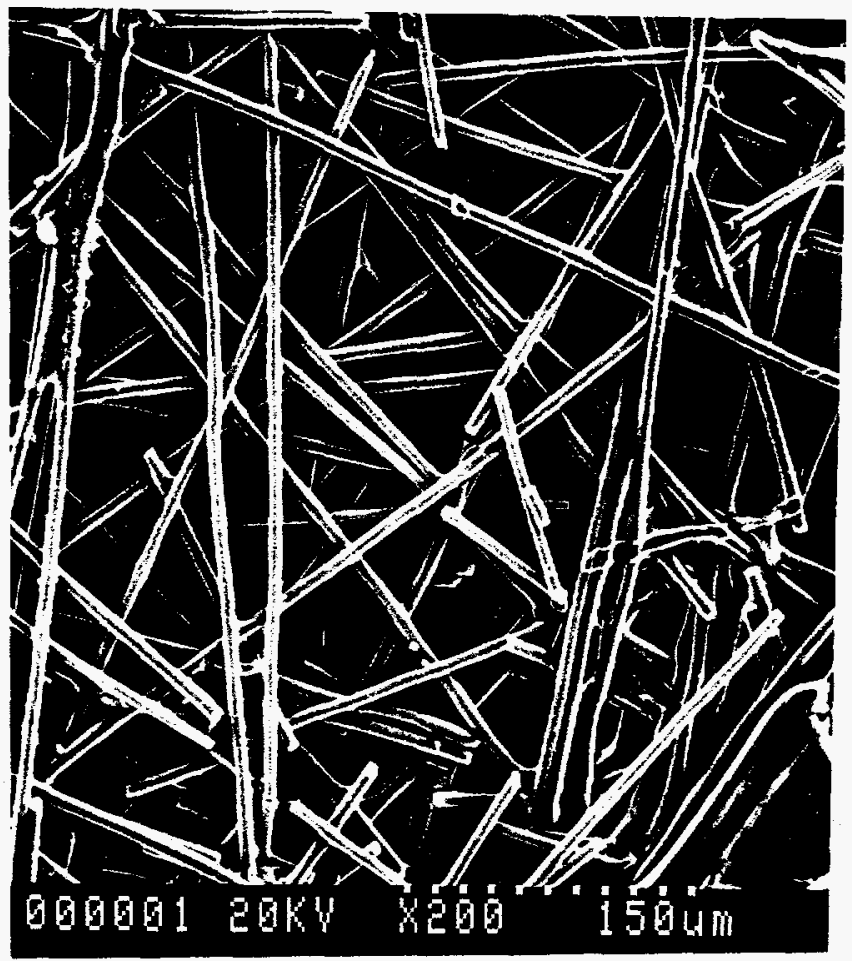

Fig. 11. Scanning electron micrographs, viewed from the top surface, of carbon substrate. 


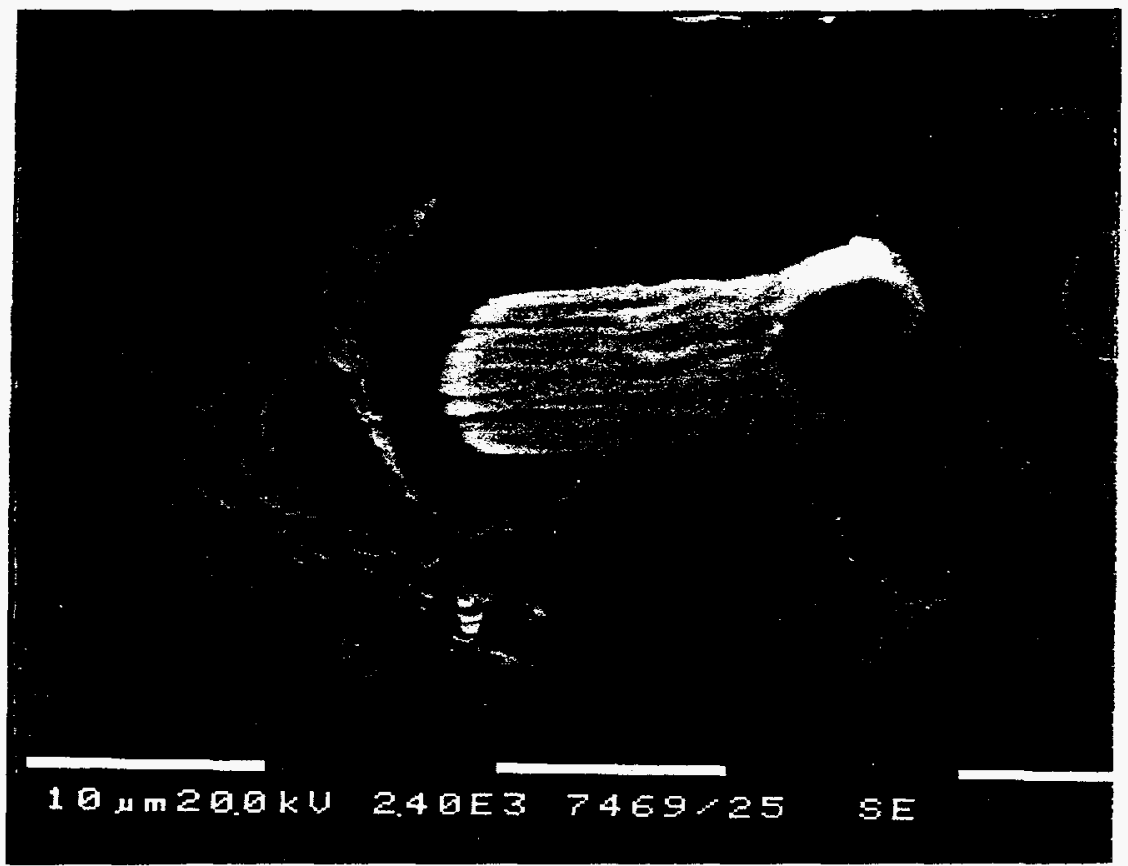

Fig. 12. Polymer growth on a carbon fibcr, cross-sectional view. The carbon fiber is the white area and the polymer is grown in a sheath around and along it.

The cell solution is the electrolytc. During polymer deposition this electrolyte contains a known concentration of the relevant polymer monomer that one wishes to grow. This electrolyte can be either an aqueous or non-aqueous solution.

\section{Conducting polymer testing: Cyclic Voltammetry}

Cyclic Voltammograms ( $\mathrm{CV}$ ) provide essential information on the charge storage capabilities of an electrode. As voltage is cycled across the cell, a current response is measured, as seen in Figure 13. The voltage is increased linearly with time (i.e. is made more positive) and the current density required to achieve the respective overvoltage is drawn by the cell. 


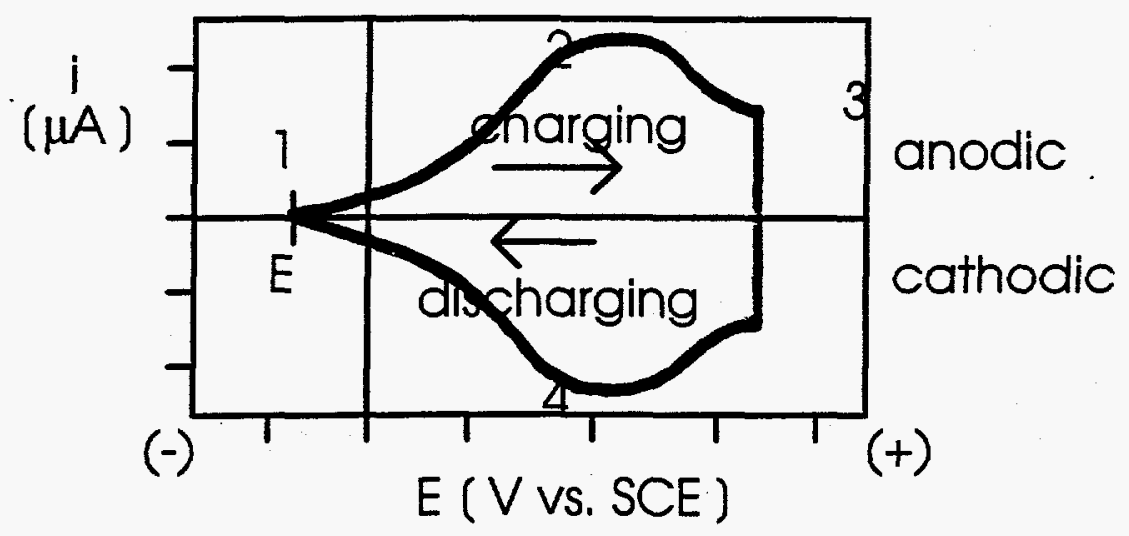

Fig. 13. An example of a typical cyclic-voltammogram, current vs. voltage.

The voltage scan begins where no cell reaction occurs, i.e. no current is drawn (point 1). The voltage is then increased (point 2) to potentials where p-doping (oxidation) occurs. The applied potential, however, must be carefully considered. Application of a potential too large will result in either electrolyte reactivity (for example electrolysis of water in an aqueous electrolyte) or polymer degradation. The peaks observed in Figure 13 (point 2 and 4) are a result of the competition of two factors: the increase in the net rate of oxidation (reduction) as the potential is made more positive (negative) and the developing (diminishing) of a depletion layer in the electrolyte across which reactant must diffuse to reach the interface of the electrode[11].

The net stored charge associated with the electrode is given by the area under the anodic peak $(1 \rightarrow 2 \rightarrow 3)$, and the discharge is given by the area under the cathodic peak ( 3 $\rightarrow 4 \rightarrow 1$ ), as shown in Figure 13[1,9]. The stored charge may be determined numerically by using equation 3 .

$$
Q=\int \mathbf{i d t}
$$

The voltage applied to the electrode yields important information on the amount of stored energy, as indicated in equation 1. Since energy stored is dependent on the 
square of the voltage, the stored energy is considerably limited by the voltage. Any increases in the voltage applied across an electrode, without degrading the electrolyte, will be beneficial to the capacitors' performance, in terms of energy storage.

Cyclic voltammetry is an essential technique in evaluating the capacitive performance of an electrochemical cell. In the study presented here, the technique illustrates the ability of an ion in the electrolyte to manipulate its way towards and into the charged polymer. The conductivity of the polymer, as a result, is directly proportional to the accumulated charge held by the polymer. Therefore, the atomic structure of the polymer and the morphology of the deposit couple to determine the capacitive performance of the electrode.

The use of conducting polymers as the active material in electrochemical capacitors is quite exciting. It is in this endeavor, to participate and contribute that I present the following objective and hypothesis:

\section{Objective}

To study the effect of variations in the growth parameters of electrochemically deposited conducting polymers on their morphology; and on subsequent electrochemical capacitive performance. 


\section{Hypothesis}

A conducting polymer's electrochemical capacitive performance is greatly affected by its morphology, i.e. the structure of the polymer/electrolyte interface. Growth conditions for optimum performance can be determined.

\section{Experimental Methods}

To conduct this research an electrochemical laboratory is required. The primary components of this laboratory (i.e. the glove box and testing equipment) are shown in Figure 14. The (a) glove box is essential for conducting the experiments with nonaqueous electrolytes. An (b) EG\&G Model 273 Potentiostat/Galvanostat is a current and voltage source for the desired testing methods. A (c) computer interface allows for easy control of the test. Also shown in Fig. 14 is an (d) EG\&G Model 5210 Lock-In Amplifier which may be used for impedance measurements. Figure 15 shows the supplies and equipment which are located inside the glove box. These supplies include chemical containers, growth cells, electrodes, waste containers (solid/chemical), scales, clamps and posts, syringes, and electric feedthroughs.

There are many considerations one must entertain when conducting this and any research project. The most important, which should never be compromised, is that of safety. A majority of the chemicals are hazardous in nature. Precautions in handling these hazardous chemicals, and there proper disposal, ensures safety. Another area of concern is the ventalation system involved with the glove box. To ensure the safety of all laboratory workers it is imperitive that all glove box outlets were ventilated through a hood. 
In general the experimental methodology for this research is straight forward. The experimental methods include: clectrode and chemical preparation, and polymer growth and testing.

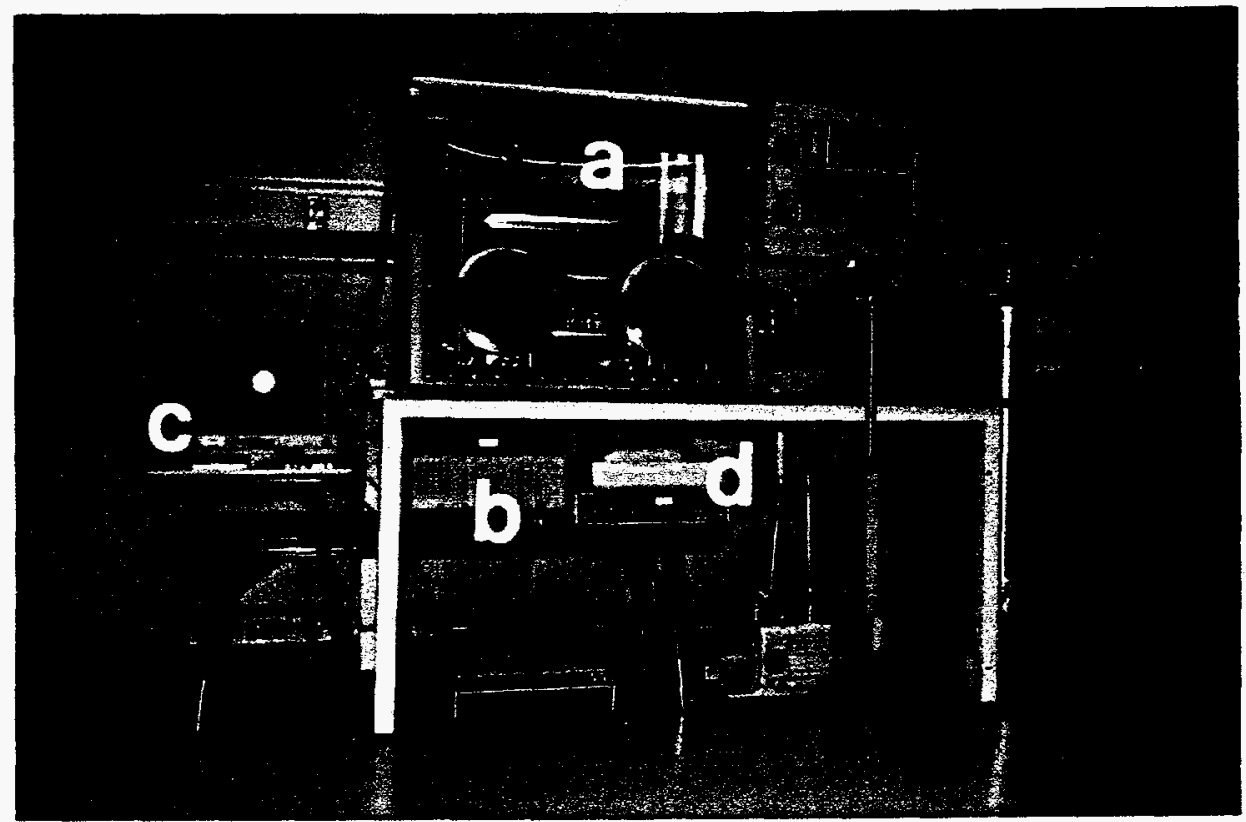

Fig. 14. Primary components of an electrochemical laboratory which were used throughout this research. The equipment pictured include: (a) Vacuum Atmosphere Company glove box, (b) EG\&G Model 273 Potentiostat/Galvanostat, (c) IBM computer, and (d) EG\&G Model 5210 Lock-In Amplifier.

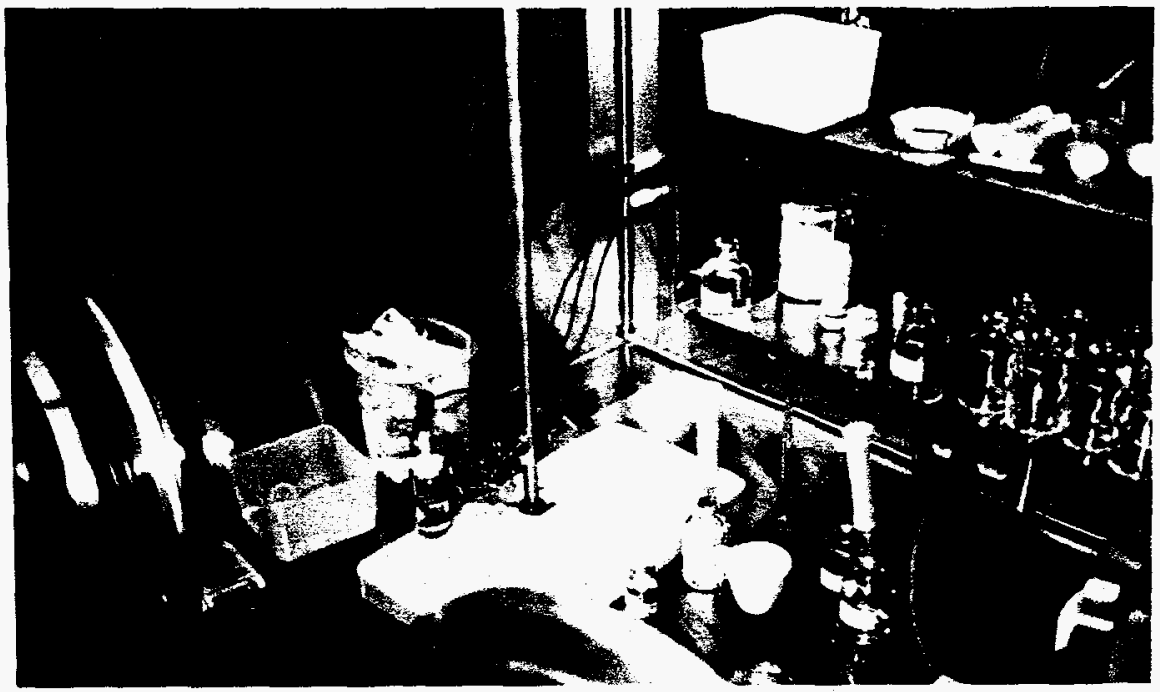

Fig. 15. Laboratory supplies and equipment found inside the glove box, included are: chemical containers, growth cells, electrodes, waste containers (solid/chemical), scales, clamps and posts, syringes, and clcctric feedthroughs. 


\section{Electrode Preparation:}

The carbon paper utilized as the substrate for polymer deposition, the working electrode, was purchased through Spectracorp. The carbon paper was sectioned into $1 \mathrm{~cm}^{2}$ electrodes. A triangular portion was left to attach a platinum wire to complete the electrode. The wire is attached with a conducting silver epoxy, and an outer-coat of ordinary insulating epoxy is then applied. Figure 16 details this procedure. The counter electrode consist of a platinum mesh, approximately $1 \mathrm{~cm}^{2}$ surface area, spot welded to a platinum wire. The reference electrode is a $\mathrm{Ag} / \mathrm{Ag}+$ reference electrode, and is utilized as a voltage reference [4]. The glass body tip of the reference electrode is initially topped with a porous vycor plug. Heat-shrinking of a Teflon tube assures this seal. The reference electrode was then placed into 1M TMAT in acetonitrile to allow sufficient time to wet the porous plug. After 1 hour the electrode body was removed and filled with a solution of $15 \mathrm{mM}$ silver nitrate in $1 \mathrm{M}$ TMAT in acetonitrile. A polished and cleaned silver wire is then immersed into the silver nitrate solution, and the body sealed with a Teflon cap. The assembly is schematically shown in Figure 17.

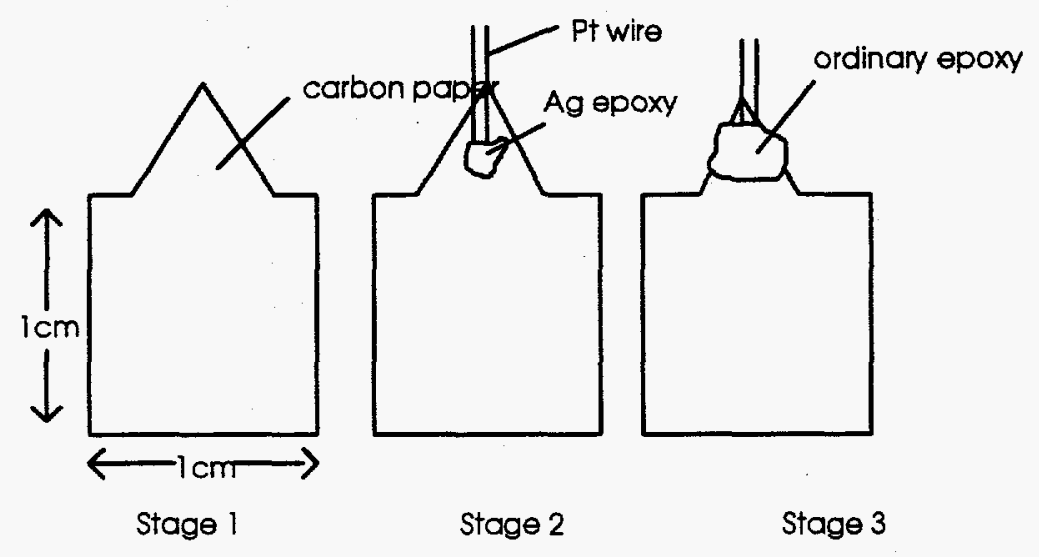

Fig. 16. Procedure for carbon electrode preparation. 


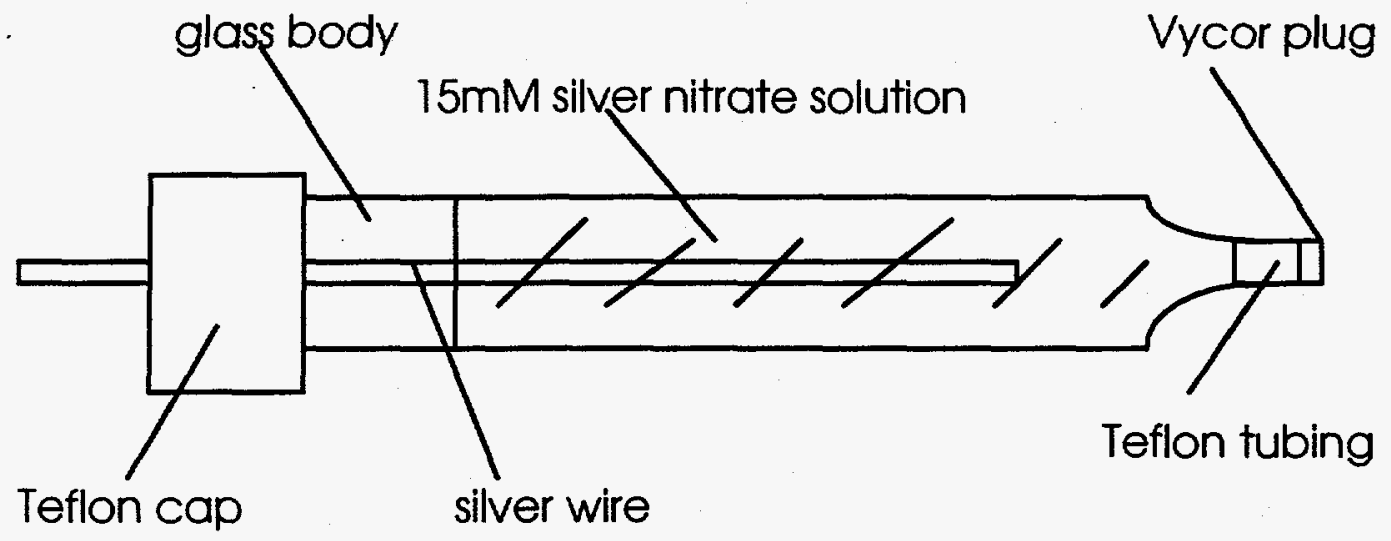

Fig. 17. $\mathrm{Ag} / \mathrm{Ag}+$ reference electrode assembly.

Activated Alumina:

To insure that the effects of oxygen are minimized in both growing polymer films and testing electrolyte solutions, activated alumina is placed into the solutions as an oxygen and moisture getter. Heat treating the activated alumina prior to use removes excess moisture contained in the powder itself. To accomplish this the alumina is placed in a ceramic crucible and dried in an oven at $550^{\circ} \mathrm{C}$ for 8 hours in air. It is then placed in the transfer chamber of the glove box while still hot $\left(250\right.$ to $\left.300^{\circ} \mathrm{C}\right)$ and brought under vacuum. Next it is cooled prior to purging with nitrogen and transferred into the glove box. This procedure was utilized in the non-aqueous electrolyte experiments.

General Procedures:

-All the non-aqueous polymer growth experiments were done in an inert atmosphere and at room temperature, utilizing a glove box. Aqueous electrolyte, polymer growth 
experiments were conducted under argon purging. Prior to any testing or polymer growth, argon was bubbled into the electrolyte for approximately 10 minutes using a submerged capillary feed tube. Just prior to initiating polymer growth, the tube was positioned just above the electrolyte surface so as to create a "blanket" of argon.

- Stirring was not employed in any of the deposition experiments.

-All electrochemical growth experiments were performed in $20 \mathrm{ml}$ glass vials and at room temperature.

-Cell assembly was completed as described in earlier sections.

-The selection of the electrolyte depends on the desired polymer. For example, during polymer growth it is necessary to have a specified concentration of the monomer in solution.

-Prior to the completion of the cell it is essential that approximately $0.3 \mathrm{~g}$ of activated alumina be placed in the non-aqueous electrolytes.

- The model 273 EG\&G Potentiostat/Galvanostat allowed for a constant oxidation current necessary for polymer deposition and a programmed variation potential for the cyclic voltammetry measurements. Specially programmed software provided by Princeton Applied Research allowed for an interface with the EG\&G unit via an IBM computer. This software runs all experiments, and saves and prints the data.

-After the polymer is grown (or tested) it was removed from the electrolyte solution and rinsed in acetonitrile. It was then dried for morphological analysis via scanning electron microscopy. 


\section{Results and Discussion}

\section{Polyaniline (PAni):}

The morphology and dopability of the conducting polymer polyaniline, as grown under different electrochemical conditions, was initially studied. The growth parameters varied were the following: growth current density, the nature of the electrolyte and the electrode substrate. Scanning electron microscopy and cyclic voltammetry provided information on the polymer morphology and charge/discharge performance, respectively.

PAni was grown from its monomer constituent out of aqueous hydrochloric acid. A simplified mechanistic view of the electrochemical polymerization reaction is given in Figure 18.

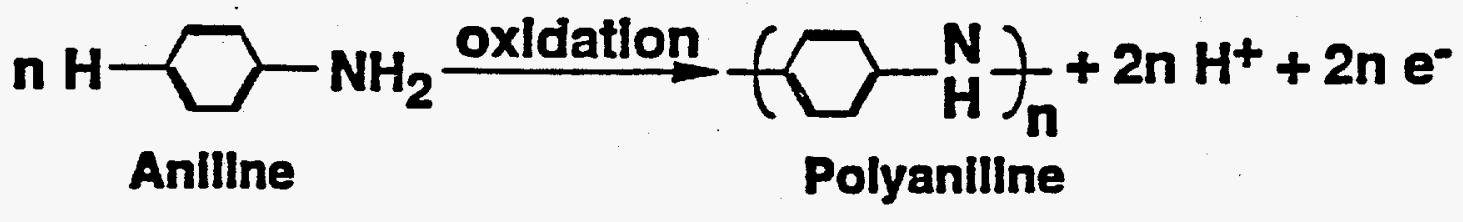

Fig. 18. Electrochemical polymerization reaction of polyaniline from its monomer constituent.

\section{Effect of growth current density}

Polyaniline was grown on carbon substrates at different constant oxidation current densities. Polymers were grown at $10 \mathrm{~mA} / \mathrm{cm}^{2}$ for $1,000 \mathrm{~s}, 1 \mathrm{~mA} / \mathrm{cm}^{2}$ for $10,000 \mathrm{~s}$, and $100 \mu \mathrm{A} / \mathrm{cm}^{2}$ for $100,000 \mathrm{~s}$. This insured that equal amounts of PAni would be deposited, 
as current multiplied by time gives the growth charge, the total growth transfer during growth. Therefore, if one doubles the amount of growth time the amount of charge associated with the polymer will approximately double as well. The current density is based on the projected area, and thus greatly overestimates the actual current density on these carbon paper substrates.

Utilizing the growth parameters described above, it was observed that the morphology of PAni will vary with growth current density for a constant total charge transfer. Photomicrographs of respective PAni electrodes are presented in Figure $19 \mathrm{a}$ and b. Figure 19(a) shows a granular PAni morphology which formed in sheaths along the carbon fibers under the applied current density of $100 \mu \mathrm{A} / \mathrm{cm}^{2}$. At $10 \mathrm{~mA} / \mathrm{cm}^{2}$ the morphology is quite different from that of the former polymer, as seen in Figure 19(b). The polymer forms a network of polymer fibrils on the surface of the carbon substrate.

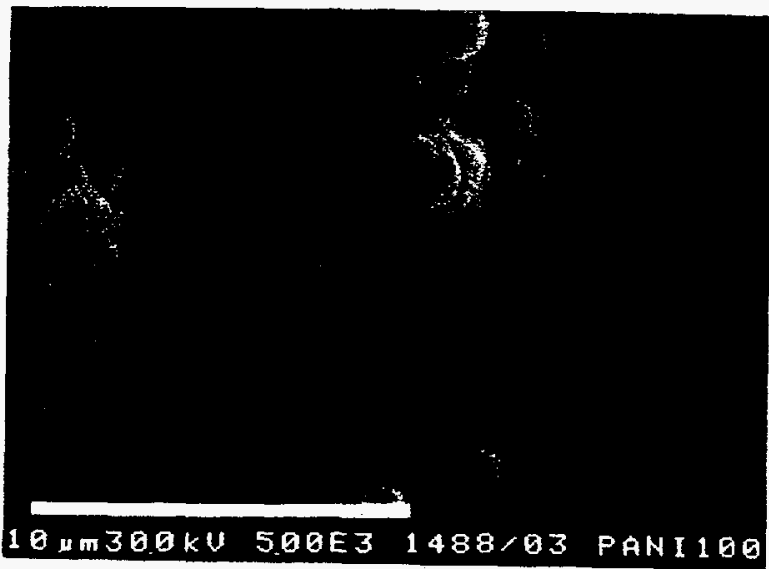

(a)

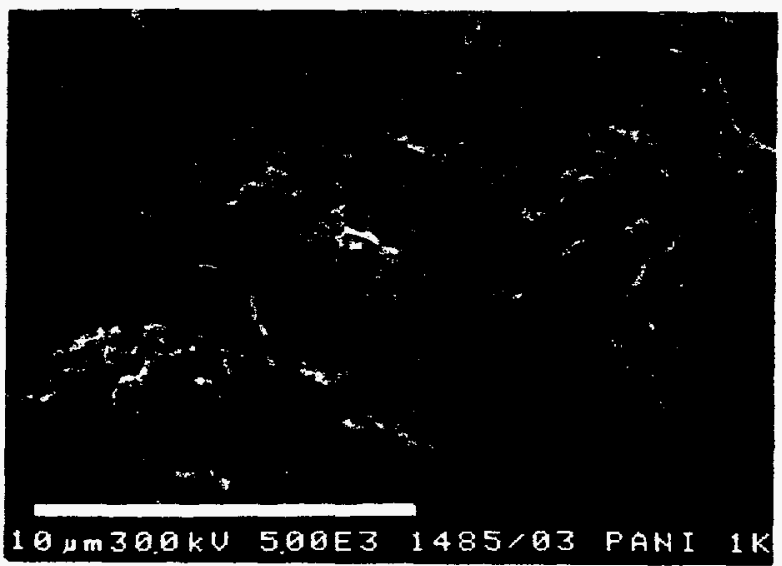

(b)

Fig. 19. Scanning electron micrographs of PAni growth at different current densities, on carbon substrates, viewed from the top surface. Effects of growth densities of $100 \mu \mathrm{A} / \mathrm{cm}^{2}$ for $100000 \mathrm{~s}$ (a) and $10 \mathrm{~mA} / \mathrm{cm}^{2}$ for $1000 \mathrm{~s}$ (b) are illustrated.

The differences in morphology reflect the rate of polymer deposition. Prior to polymer growth the monomer may be thought of as being present at equal concentrations throughout the electrolyte. As the polymer is oxidized onto the electrode a mer- 
concentration gradient develops. Monomers near the substrate oxidize at a faster rate at higher current densities. The polymer may be perceived as "reaching out" to the higher concentration electrolyte. This effect is seen by the polymers growth morphology. At low current density the monomers have time to gain access into the recesses of the carbon fiber network and grow more or less uniformly along the carbon fibers. At high current density, the regions of electrolyte within the carbon fiber network quickly become diminished of mer-units. As a result, it was observed that the higher current density yielded a polymer deposition where a majority of the product formed at the outer surface of the carbon fibers.

The post deposition charge/discharge processes were characterized via cyclic voltammetry experiments conducted in the growth electrolyte. A typical cyclic voltammogram plot is shown in Figure 20. Cyclic voltammograms show that the polymers grown at higher current densities perform better than those grown at lower densities. For example, a polymer grown at $10 \mathrm{~mA} / \mathrm{cm}^{2}$ show higher charge and better reversibility than a polymer grown at $100 \mu \mathrm{A} / \mathrm{cm}^{2}$ for otherwise equivalent deposition conditions (Fig. 20).

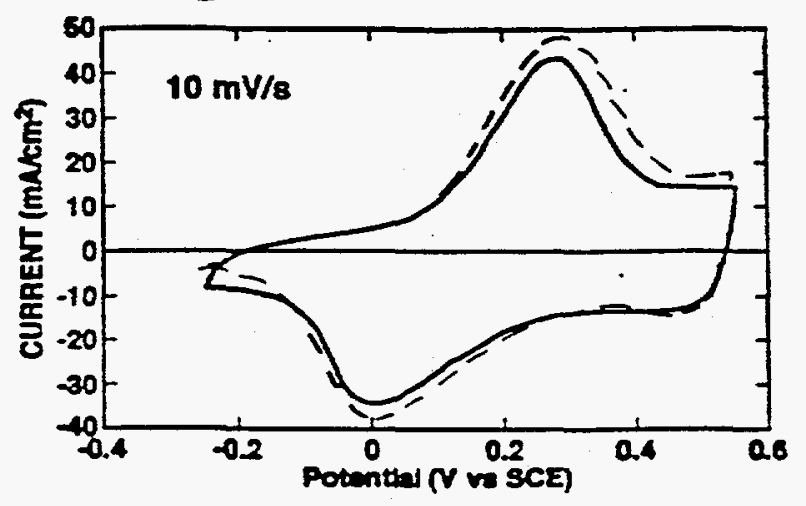

\section{$-100 \mu \mathrm{A}$ for $100000 \mathrm{~s}$ $\ldots 10 \mathrm{~mA}$ for $1000 \mathrm{~s}$}

Fig. 20. Effect of current density on cyclic voltammetry performance. PAni growth on carbon paper from a solution of $0.5 \mathrm{M}$ aniline in $1 \mathrm{M} \mathrm{HCl}(\mathrm{aq})$. 
The results of this experiment were quite encouraging. A similar study, published in the Journal of Power Sources by S. Taguchi and T. Tanaka show PAni growth morphology's similar to those presented in this report [10]. In their study, however, the experimental parameter bcing altered was the electrolyte type. The electrolytes utilized in their experiments were $1 \mathrm{M} \mathrm{HClO}_{4}$ and $0.5 \mathrm{M} \mathrm{H}_{2} \mathrm{SO}_{4}$, each containing $0.5 \mathrm{M}$ aniline. Taguchi, et al. concluded that the fibrilic PAni morphology was well suited for use in a polymer battery.

\section{Effect of acid electrolyte}

Three other electrolytes were utilized for PAni growth at $10 \mathrm{~mA} / \mathrm{cm}^{2}$ for $1000 \mathrm{~s}$, as . this current density yielded the highest charge capacity with respect to PAni morphology when the electrolyte $1 \mathrm{M} \mathrm{HCl}$ was used (last section). The three additional electrolytes tested were $0.5 \mathrm{M}$ camphorsulfonic acid, $1 \mathrm{M}$ perchloric acid [10], and $1 \mathrm{M}$ sulfuric acid [10]. Each PAni electrode was grown onto a carbon substrate in $0.5 \mathrm{M}$ aniline each respective acid solution. Figure 21 shows the cyclic voltammograms for the selected electrolytes.

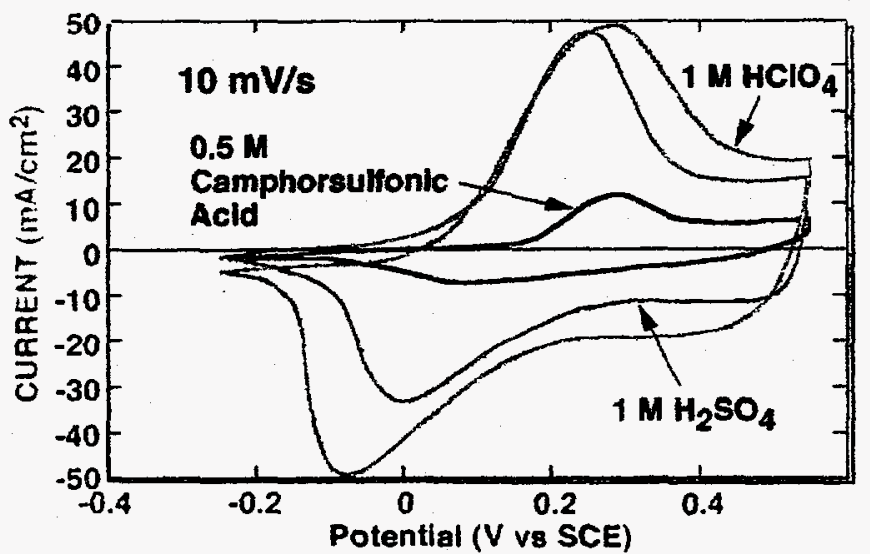

Fig. 21. Effect of growth acid electrolytes on $\mathrm{C}-\mathrm{V}$ performance. Acid electrolytes tested: $0.5 \mathrm{M}$ Camphorsulfonic acid, $1 \mathrm{M} \mathrm{HClO}_{4}$, and $1 \mathrm{M} \mathrm{H}_{2} \mathrm{SO}_{4}$ containing $0.5 \mathrm{M}$ aniline. 
In Fig. 21, perchloric acid shows some interesting behavior. This electrolyte has the highest charge storage. However, there is a lack of reversibility, illustrated by the increase of cathodic and anodic peak separations (i.e. charge/discharge hysterisis). This lack of reversibility is ultimately a hindrance to the capacitive performance of the electrode. The electrode as shown discharges at a slower rate, defeating the purpose of an electrochemical capacitor. Sulfuric acid displays less peak separation, but a considerable decrease in charge storage occurs. The camphorsulfonic acid has the worse overall performance. It was believed initially that this acid had the potential to be a strong candidate for electrolyte use because of its reported high electrical conductivity. However, as expressed earlier, it is ionic conductivity that is essential to the capacitive performance of the conducting polymer electrodes. If the ions do not have the mobility required to move to and attach themselves to the polymer, then the amount of stored charge is restricted.

The morphology of PAni growth was quite unique in each electrolyte. Very little PAni was grown onto the carbon substrate in the camphorsulfonic acid electrolyte system, as seen in Figure 22(a). Individual carbon fibers are still visible after the polymer had been deposited. The sulfuric acid electrolyte morphology resembled that of a bed of "seaweed", see Figure 22(b). The polymer in the case of the perchloric acid electrolyte deposited as a flat film with no observable porosity, as seen in Figure 22(c). A different morphology exists nearer to the carbon substrate, one similar to that of the sulfuric acid, as shown in Figure 22(c) at point A. Cracks, which are believed to have formed during polymer drying, provided access to look at the polymer's morphology near the substrate.

The morphologies obtained in these experiments are not desirable. They were either limited in the amount of deposited polymer or subsequent electrolyte access. Recalling from the previous section, the fibrilic network, characteristic of high growth 
current densities in aqueous $\mathrm{HCl}$, is proven to be the better performer, with respect to the amount of stored charge and reversibility.

(a)

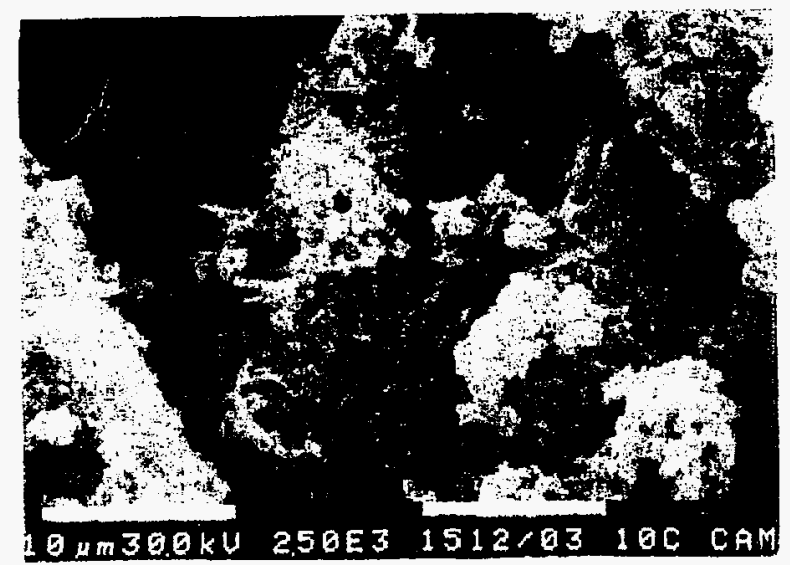

(b)

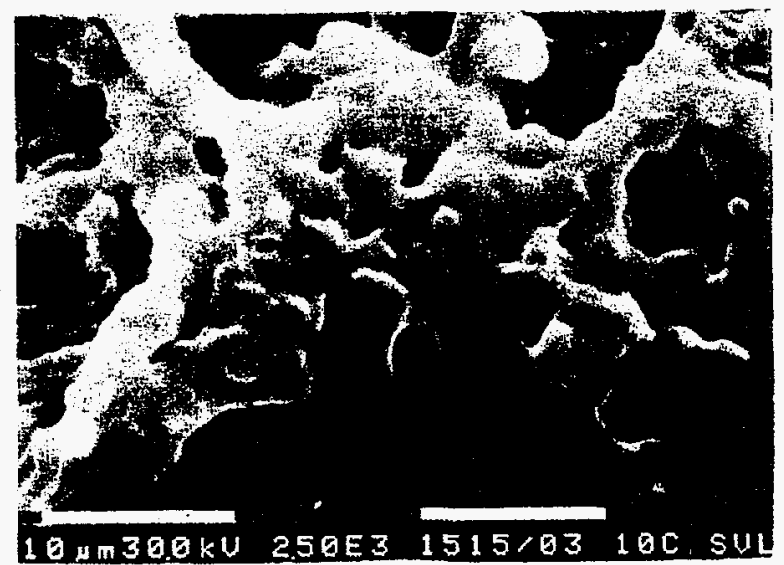

(c)

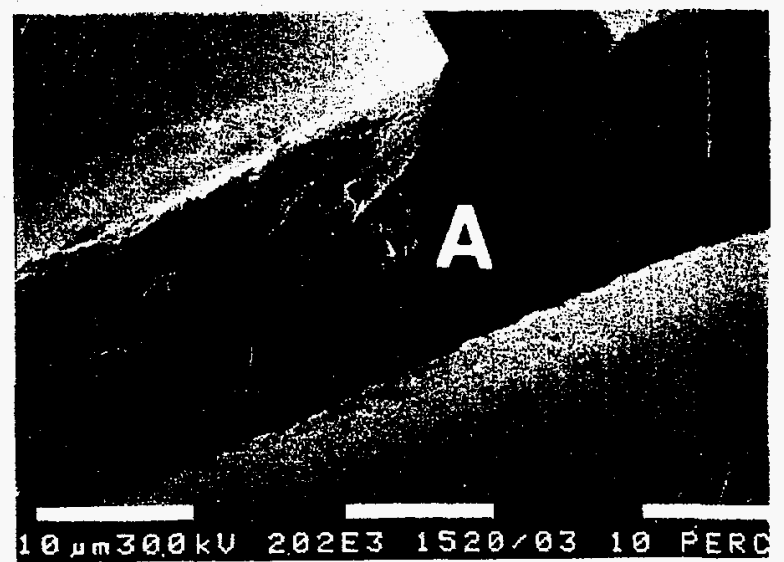

Fig. 22. Effect of acid clectrolytes on PAni morphology, top surface views. PAni grown at $10 \mathrm{~m} A$ for $1000 \mathrm{~s}$ in $0.5 \mathrm{M}$ aniline in (a) $0.5 \mathrm{M}$ camphorsulfonic acid, (b) $1 \mathrm{M} \mathrm{II}_{2} \mathrm{SO}_{4}$, and (c) $1 \mathrm{M}$ $\mathrm{HClO}_{4}$. 


\section{Effect of planar substrate}

The high current density growth conditions $\left(10 \mathrm{~mA} / \mathrm{cm}^{2}\right)$ in $\mathrm{HCl}$ provide a desirable PAni continuous film morphology. It was therefore hypothesized that the carbon substrate may not be required to obtain high surface area and high porosity polymer films. Once nucleated under a current density of $10 \mathrm{~mA} / \mathrm{cm}^{2}$, the polymer grew upon itself to form a network of polymer fibrils. Therefore, the effect of a planar substrate at high current density deposition was tested. A platinum foil was utilized as the working electrode. The polymer was deposited at $10 \mathrm{~mA}$ for 1000 s out of $0.5 \mathrm{M}$ aniline in $1 \mathrm{M} \mathrm{HCl}$ (aq).

The resulting electrode performed quite well in cyclic voltammetry experiments, as seen in Figure 23(a). The curve shows charged storage with good reversibility directly comparable to carbon substrate electrodes. Figure 23(b) shows that the morphology is essentially the same as that of the PAni grown on the previous, fibrous substrate. This result suggests the potential to reduce the weight of the electrochemical capacitor. Currently carbon substrates are utilized to provide the high surface area, high porosity microstructure for the conducting polymer. However, deposition of a polymer at high current densities yields polymer with a high surface area-high porosity morphology independent of substrate type. The use of a thin foil may then be utilized for whatever polymer thicknesses is desired. 


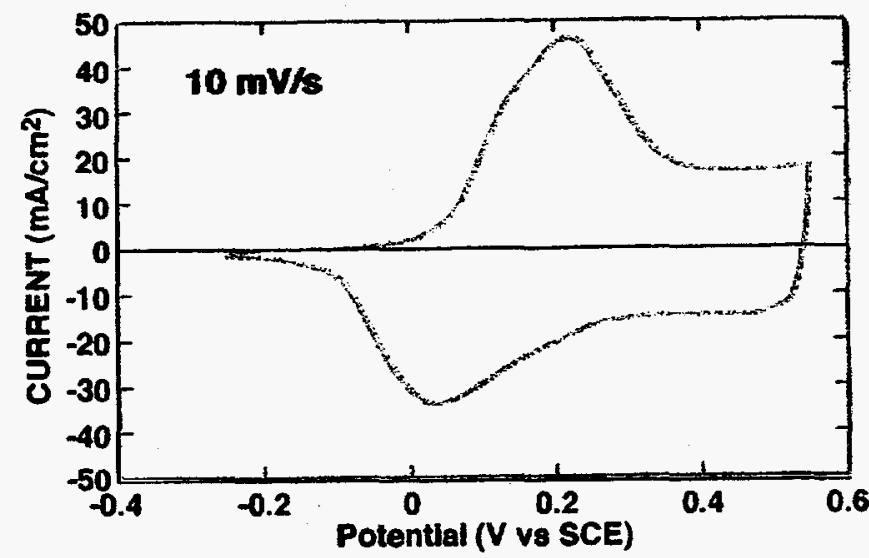

(a)

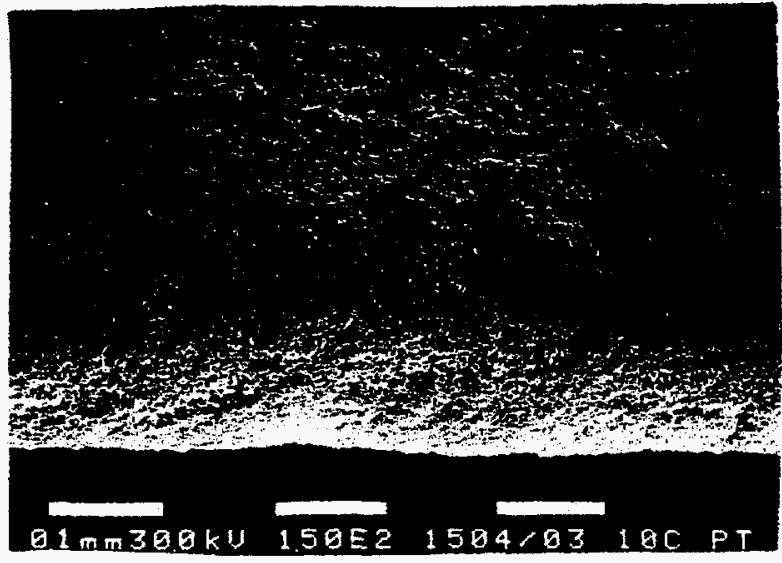

(b)

Fig. 23. Effect of a platinum planar substrate on (a) the cyclic voltammetry performance and (b) the morphology of electrochemically grown polyanilinc, grown at $10 \mathrm{~m} \Lambda$ for 1000 s out of $0.5 \mathrm{M}$ aniline in $1 \mathrm{M} \mathrm{HCl}$ (aq). The scanning electron photomicrograph shows a top surface view at a slight angle.

\section{Poly-3-(4-fluorophenyl)-thiophene (PFPT):}

In the preceding analysis PAni was characterized as a function of growth current density, growth electrolyte type, and substrate type. The results were discussed in the light of scanning electron microscopy and cyclic voltammetry experiments. A similar analysis is involved with PFPT. PFPT was characterized as a function of growth current density and electrolyte concentration. Not only was scanning electron microscopy and cyclic voltammetry utilized in the analysis, but optical microscopy and voltage vs. time plots were used as well. These methods of analysis were combined to determine the electrochemical characteristics of this novel polymer. 


\section{Deposition}

Electrochemical oxidation at constant current oxidation was the means in which PFPT polymers were deposited from non-aqueous solutions onto the fibrous carbon substrate. By monitoring the voltage at the working electrode many growth characteristics are represented. Figure 24 and Figure 25 show plots of voltage as a function of time for two typical polymer depositions. Figure 24 represents PFPT deposition in 1 M TMAT in acetonitrile at $20 \mathrm{~mA} / \mathrm{cm}^{2}$, and Figure 25 represents that at $1 \mathrm{~mA} / \mathrm{cm}^{2}$. Similar features between the two plots include a sharp voltage peak at the onset of polymer deposition (a and $\left.a^{\prime}\right)$, and a minimum ( $d$ and $c^{\prime}$ )before there is a linear increase in voltage in the later growth stages (e and $d^{\prime}$ ). The sharp peak ( $a$ and $a^{\prime}$ ) may be attributed to nucleation events

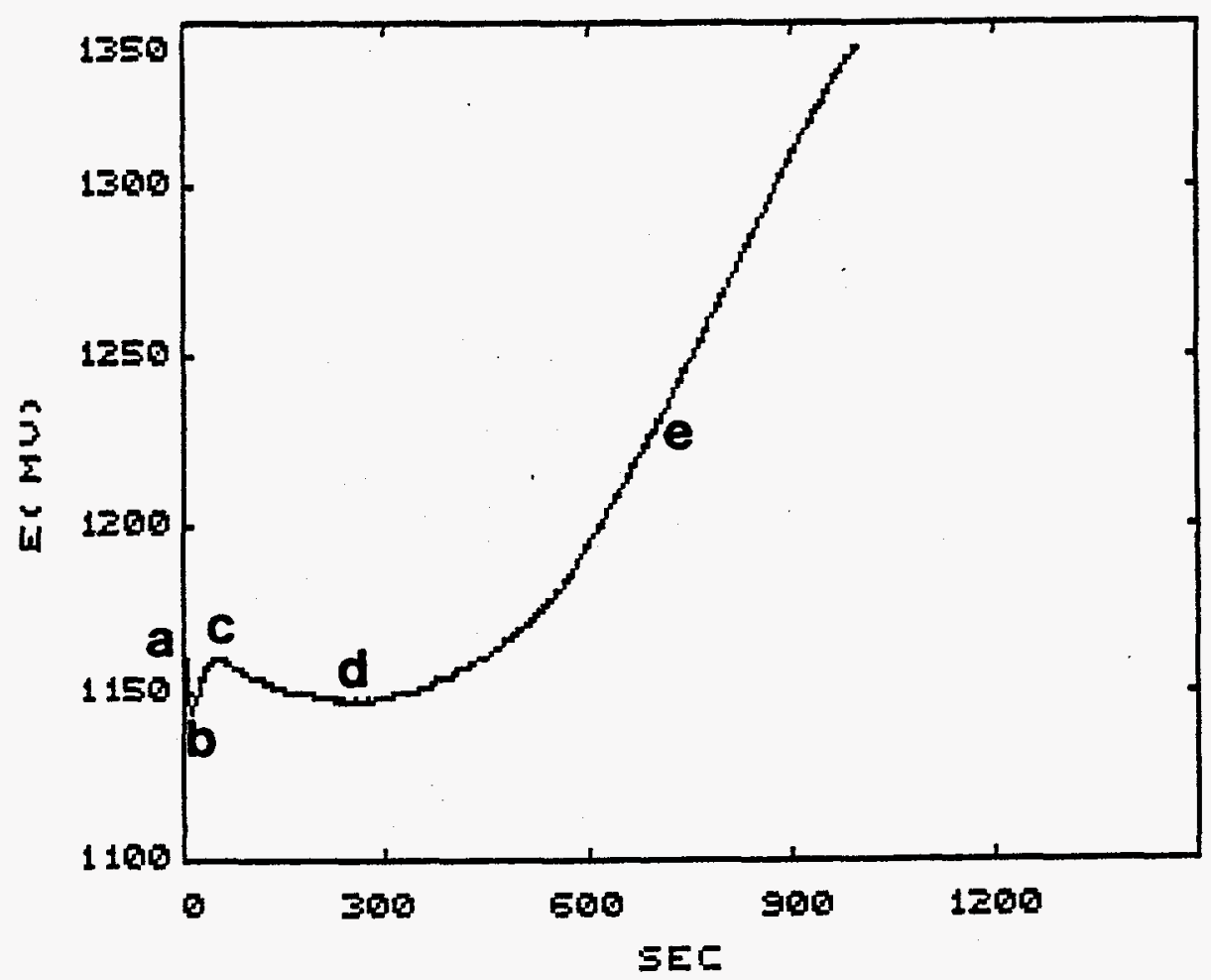

Fig. 24. PFPT deposition onto poruus carbon substrate at 20 $\mathrm{mA} / \mathrm{cm}^{2}$ from a solution of $0.1 \mathrm{M}$ TMAT in acetonitrile. 


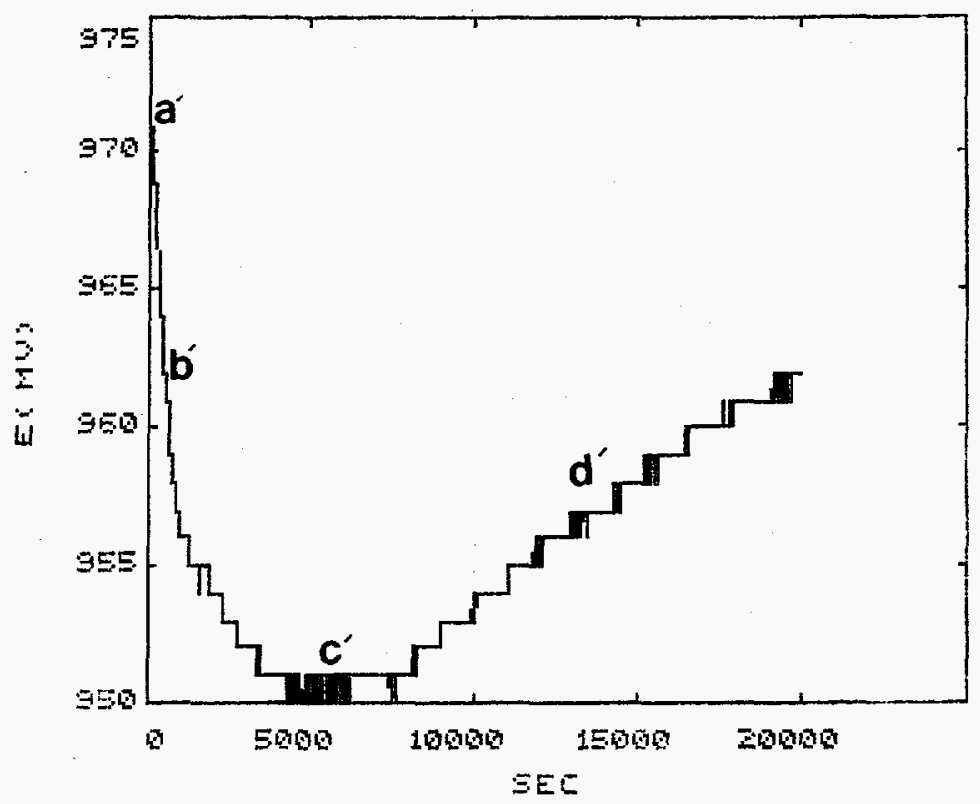

Fig. 25. PFPT deposition onto porous carbon substrate at $1 \mathrm{~mA} / \mathrm{cm}^{2}$ from a solution of $0.1 \mathrm{M}$ TMAT in acetonitrilc.

as the polymer deposits on a forcign substrate, as shown in Figure 26 (point a in Fig. 24). As the process continues the amount of voltage necessary to maintain the constant current is decreased as the polymer deposits onto a polymer layer rather than at the carbon surface. $\Lambda$ discontinuous deposition of this polymer layer is shown in Figure 27 (point $\mathrm{c}$ of Fig. 24). The minimum and subsequent lincar voltage increase at the later stages is believed to be a result of a

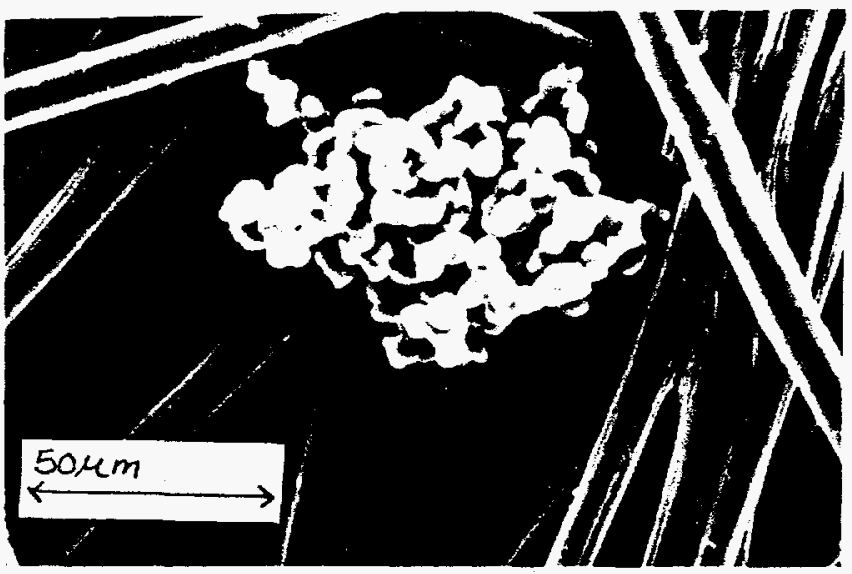

Fig. 26. Initial stages of PFPT Deposition onto carbon substrate at $20 \mathrm{~mA} / \mathrm{cm}^{2}$ for 5 scconds[face view]. 


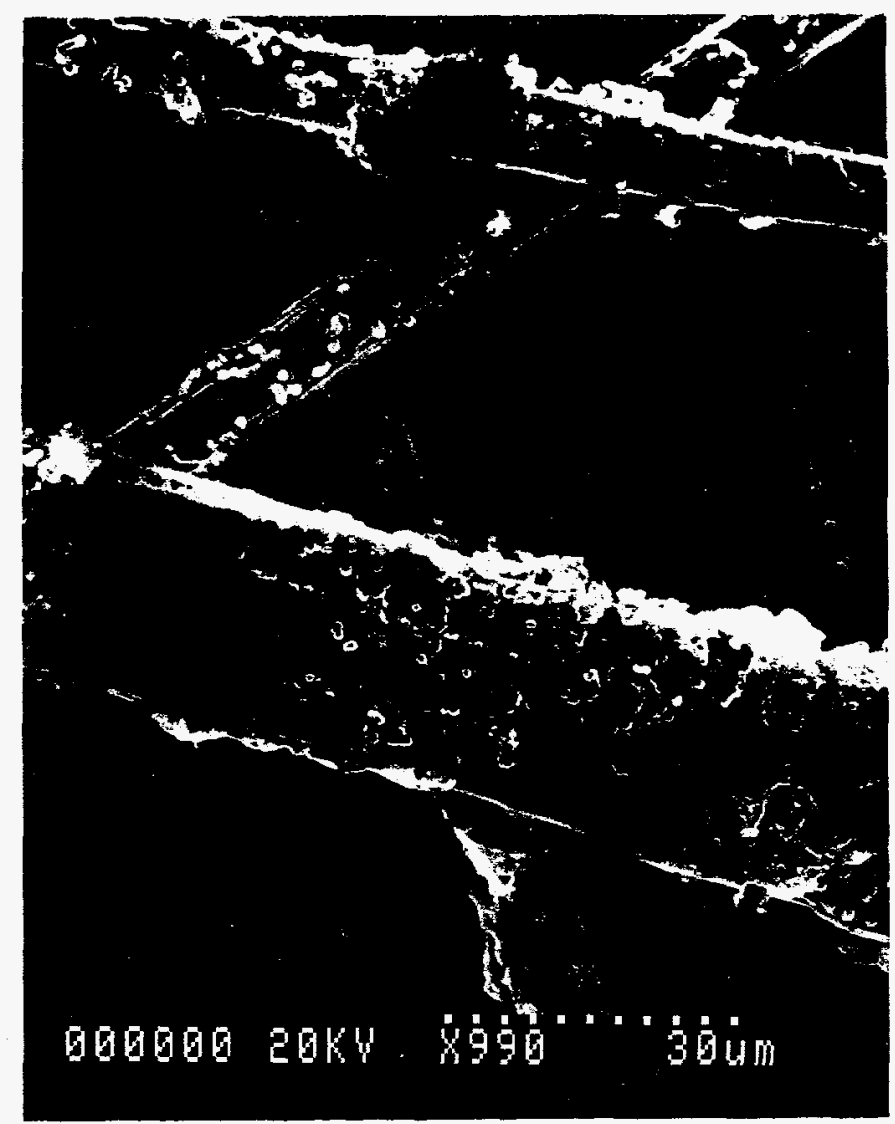

Fig. 27. Discontinuous PFPT layer on carbon libers at $20 \mathrm{~m} \Lambda / \mathrm{cm}^{2}$ for 100 seconds[face view].

reduction in electrical conduction in the polymer films as the film increases in thickness, and/or a near-electrode depletion of the monomer from the growth solution. The linear voltage increase (regions e and d' in Fig. 24 and 25, respectively) suggests a resistance development.

Photomicrographs will show in the following sections that the amount of PFPT deposited at the substrate surlace is greatcr at a current density of $20 \mathrm{~mA} / \mathrm{cm}^{2}$. Thereforc, the effect of monomer depletion and/or polymer resistivity is expected to be more significant for a polymer deposited at $20 \mathrm{m \Lambda} / \mathrm{cm}^{2}$ than at lower current density. As Figures 24 and 25 indicate, the resulting voltagc increase occurs at a steeper slope at 20 $\mathrm{mA} / \mathrm{cm}^{2}$ (e and $\mathrm{d}$, respectively).

Differences in the curves of Figure 24 and 25 arise approximatcly at $1-2 \mathrm{C}$ of accumulated growth charge (b and $b^{\prime}$ ). At $20 \mathrm{~mA} / \mathrm{cm}^{2}$ the initial voltage peak (due to 
nucleation) is followed by a voltage decrease, but then a local minimum (b) and maximum occur (c). This feature is absent during the $1 \mathrm{~mA} / \mathrm{cm}^{2}$ PFPT growth. Such a feature is likely a result of a mass transport limitation occurring through the thickness of the carbon electrode, a result of the higher growth currents. Soon after the local maximum the polymer ceases depositing throughout the thickness and only accesses the outside surfaces. This transition from inner to outer deposition occurs gradually if at all at lower current density and the deposition rate is so slow that there are no mass transport difficulties: therefore, these peaks are not observed. The following photomicrographs support this explanation of the effect of current density on the through-thickness polymer deposition. Figure 28 and Figure 29 are photomicrographs of electrode cross-sections after polymer deposition at $20 \mathrm{~mA} / \mathrm{cm}^{2}$ for 1000 seconds and $1 \mathrm{~mA} / \mathrm{cm}^{2}$ for 20000 seconds, respectively. Figure 28 shows that a majority of the polymer has deposited on the outside surfaces of the electrode (area A), rather than through the thickness (area B). The lack of polymer through the thickness of this electrode is illustrated further in Figure 30 , which shows the same cross-section at a higher magnification.

PFPT deposited at $1 \mathrm{~mA} / \mathrm{cm}^{2}$ yields much more polymer throughout its thickness at early times (point $c$ and d' in Fig. 24 and 25, respectively), as seen in Figure 29. This supports the rationale that the absent peaks in Figure 25 are indeed a result of a gradual deposition transition from inner to outer deposition onto the carbon substrate. A comparison of individual carbon fibers located at the center of the electrodes (Figures 28 and 29) is presented in Figure 31. Figure 31 (a) shows a cross-section of a carbon fiber after PFPT deposition at $20 \mathrm{~mA} / \mathrm{cm}^{2}$, and Figure 31 (b) shows that of a $1 \mathrm{~mA} / \mathrm{cm}^{2}$ PFPT deposition. PFPT deposited at the lower current density acquired a considerable increase in the amount of polymer deposited throughout the electrode thickness. An increase in thickness of the deposited polymer at the lower current density is approximately $5 \mu \mathrm{m}$. 


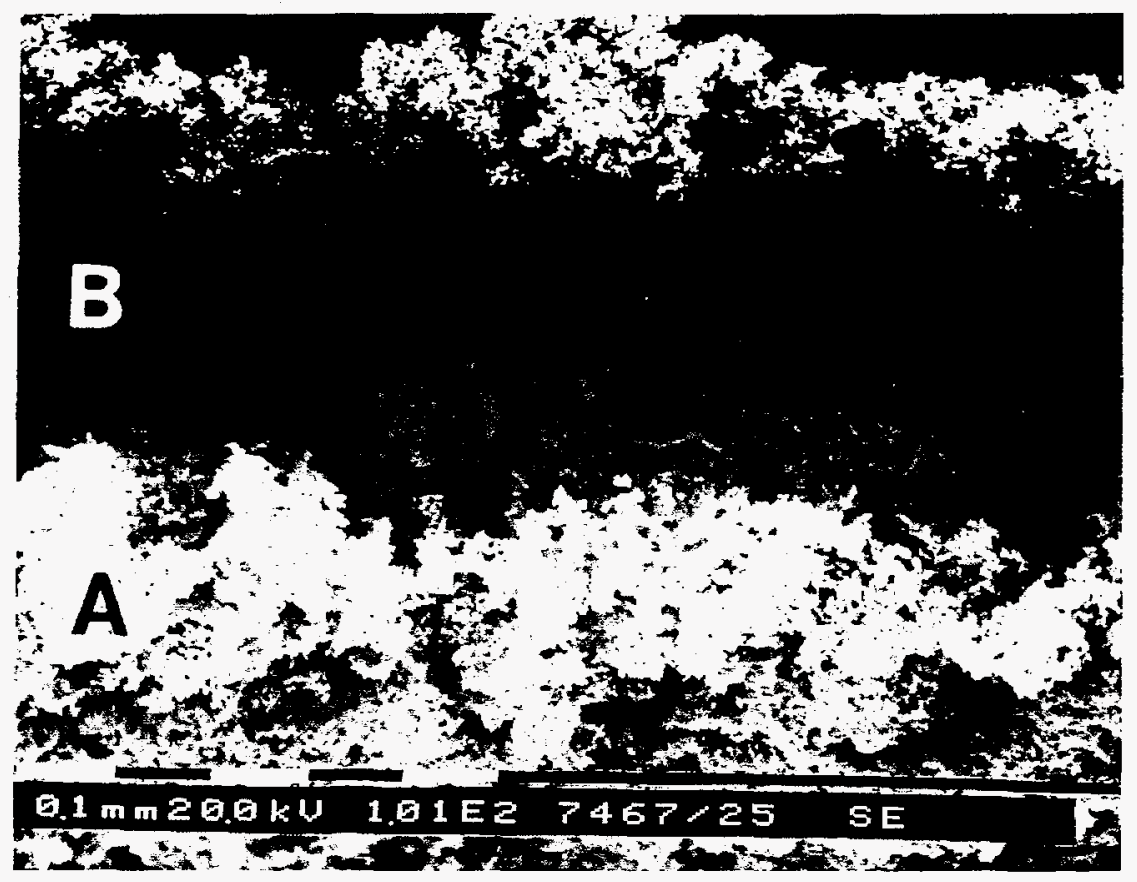

Fig. 28. Cross-section of carbon electrode after polymer deposition at 20 $\mathrm{mA} / \mathrm{cm}^{2}$ for $1000 \mathrm{~s}$ in $0.1 \mathrm{M} \mathrm{FPT}$ in $1 \mathrm{M}$ TMAT in acetonitrile.

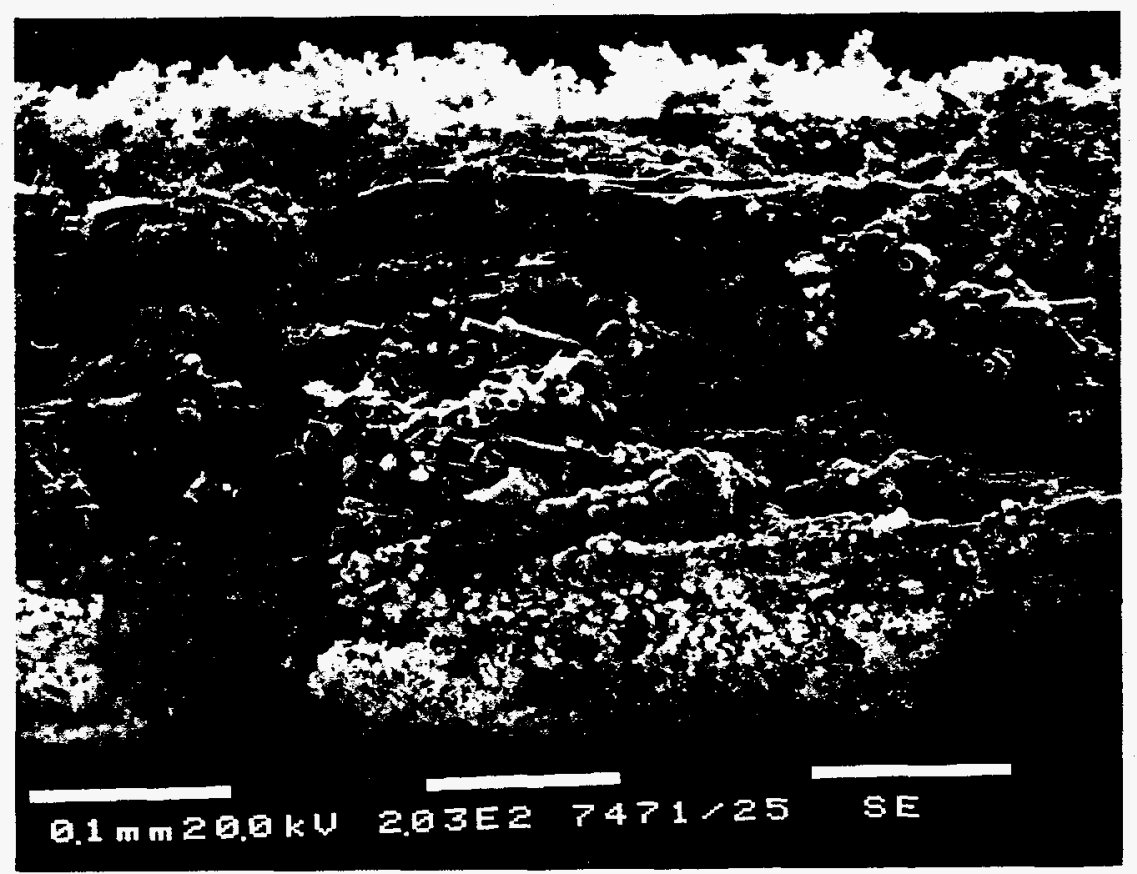

Fig. 29. Cross-section of carbon electrode after polymer deposition at 1 $\mathrm{mA} / \mathrm{cm}^{2}$ for 20000 s in $0.1 \mathrm{M} \mathrm{FPT}$ in $1 \mathrm{M}$ TMAT in acetonitrile. 


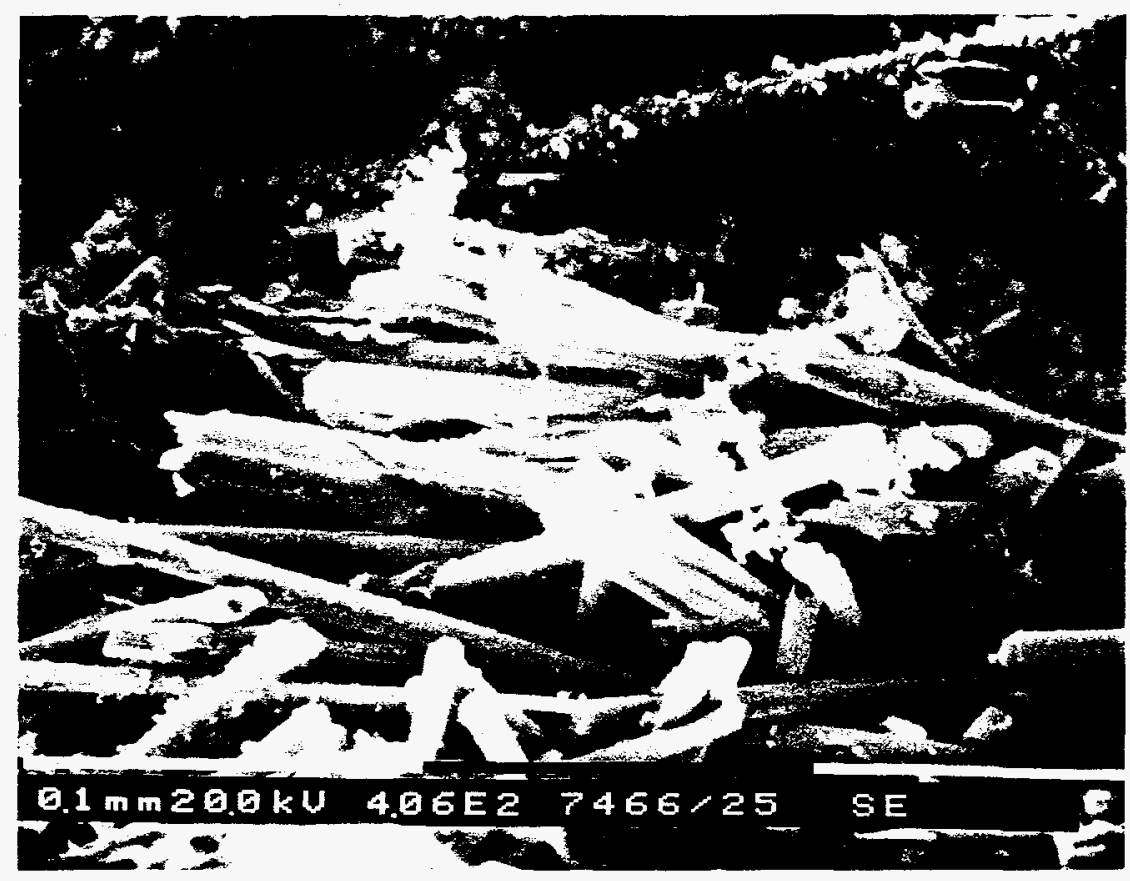

Fig. 30. Cross-section of carbon electrode after polymer deposition at 20 $\mathrm{mA} / \mathrm{cm}^{2}$ for $1000 \mathrm{~s}$ in $0.1 \mathrm{M} \mathrm{FPT}$ in $1 \mathrm{M} \mathrm{TMAT}$ in acctonitrile. 
(a)

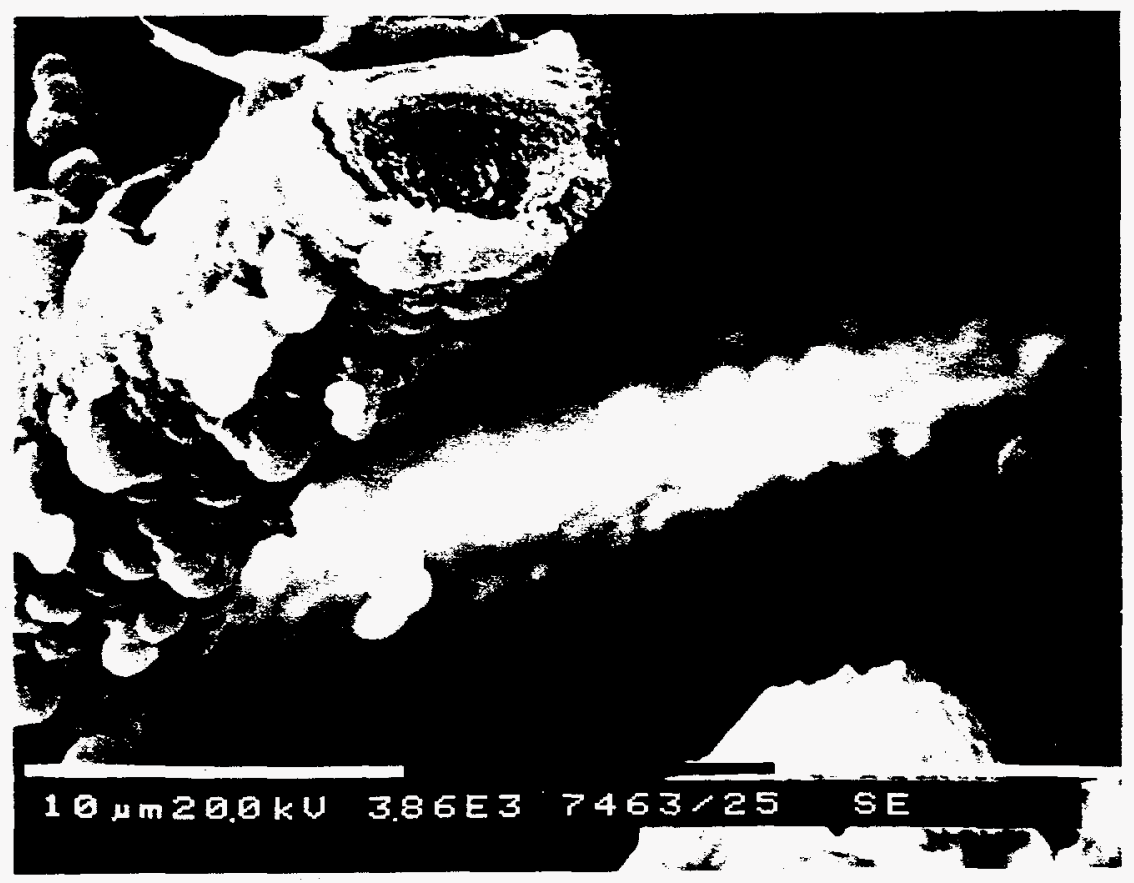

(b)

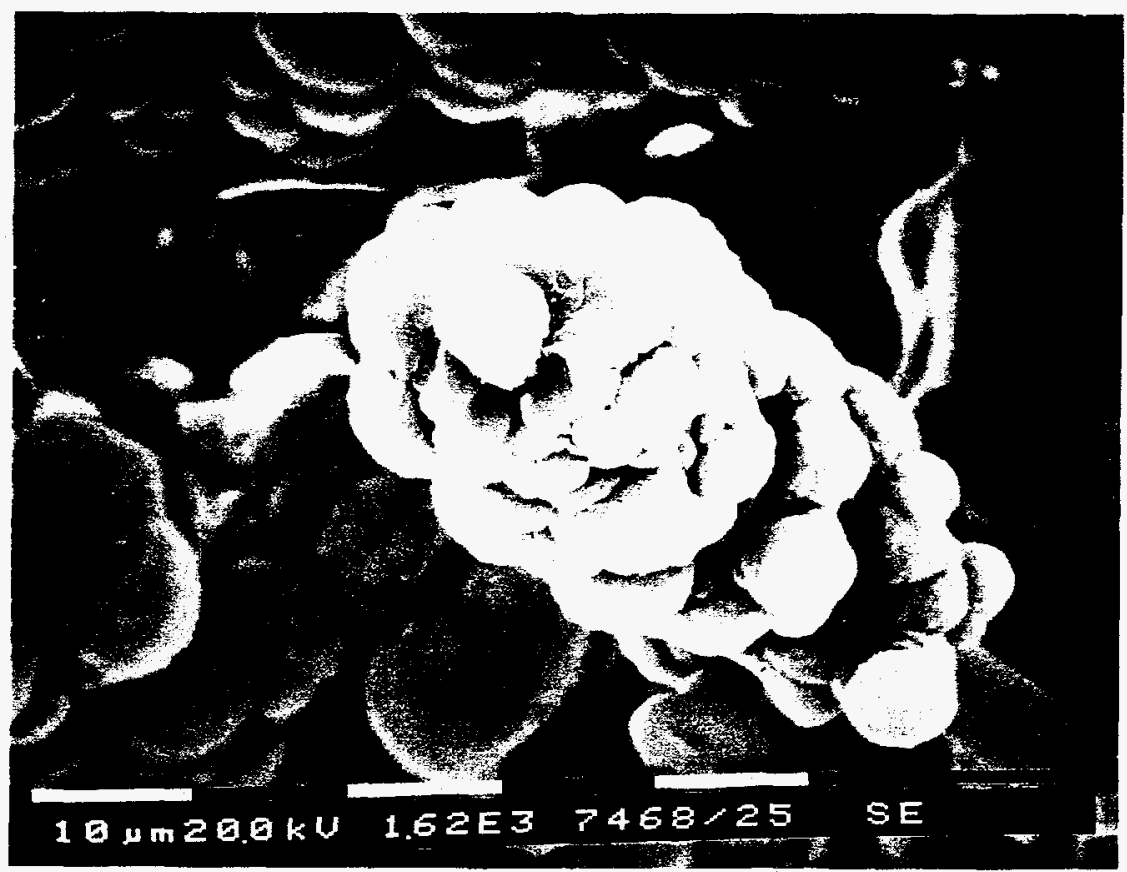

Fig. 31. Cross-section of carbon elcctrode fiber after polymer deposition at (a) $20 \mathrm{~mA} / \mathrm{cm}^{2}$ for $1000 \mathrm{~s}$ and (b) $1 \mathrm{~mA} / \mathrm{cm}^{2}$ for $20000 \mathrm{~s}$ in $0.1 \mathrm{MFPT}$ in $1 \mathrm{M}$ TMAT in acetonitrile. 


\section{Effect of growth current density}

PFPT was grown on a carbon substrate at different constant oxidation current densities. Polymers were grown at $20 \mathrm{~mA} / \mathrm{cm}^{2}$ for $200 \mathrm{~s}$ and $1000 \mathrm{~s}, 10 \mathrm{~mA} / \mathrm{cm}^{2}$ for $400 \mathrm{~s}$ and $2000 \mathrm{~s}$, and $1 \mathrm{~mA} / \mathrm{cm}^{2}$ for $4000 \mathrm{~s}$ and $20000 \mathrm{~s}$.

Cyclic voltammograms show the differences in stored charge from the three different growth densities. Figure 32 shows the $\mathrm{p}$ - and n-doping of PFPT films grown at $20 \mathrm{~mA} / \mathrm{cm}^{2}$ for $200 \mathrm{~s}, 10 \mathrm{~mA} / \mathrm{cm}^{2}$ for $400 \mathrm{~s}$, and $1 \mathrm{~mA} / \mathrm{cm}^{2}$ for $4000 \mathrm{~s}$. In order to present both $\mathrm{p}$ - and $\mathrm{n}$-doping the polymer was cycled from -2.4 volts to 0.8 volts. The PFPT films grown at the higher current densities show an increase in the amount of stored charge: i.e., an increase in electrochemical performances.

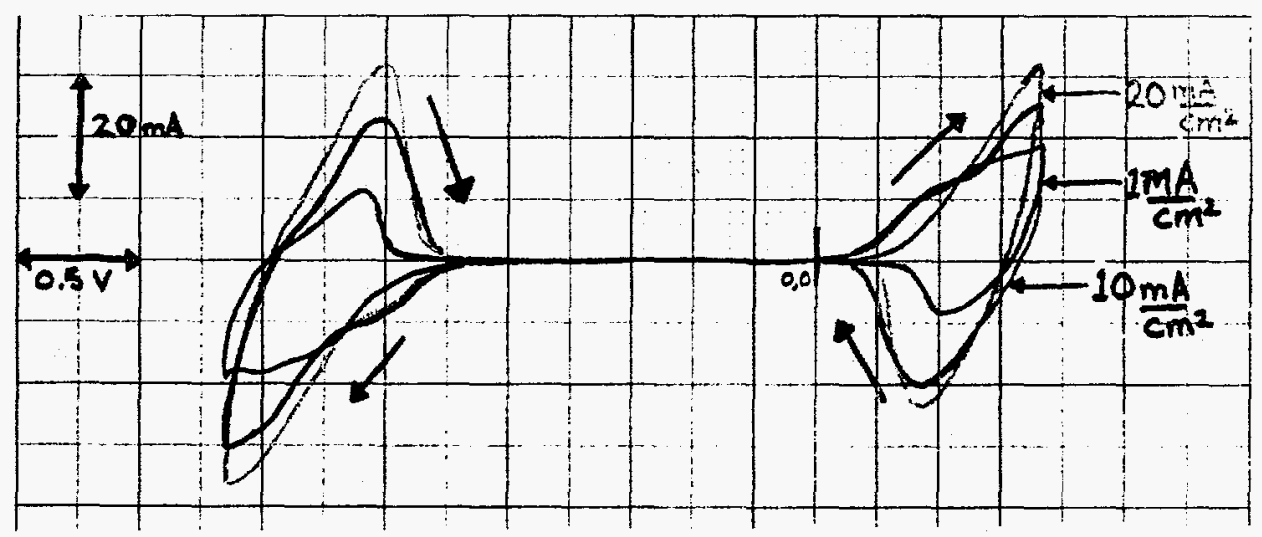

Fig. 32. Effect of growth current density on cyclic voltammetry of electro-deposited PFPT from a solution of $0.1 \mathrm{M} \mathrm{FPT}$ in $1 \mathrm{M}$ TMAT in acetonitrile with equivalent growth charge, $4 \mathrm{C}$. Sweep rate $=25 \mathrm{mV} / \mathrm{s}, \mathrm{x}$-axis $=0.5 \mathrm{~V} / \mathrm{inch}, \mathrm{y}$-axis $=20 \mathrm{~mA} /$ inch.

The cause of such performance differences is most likely a result of morphology differences as discussed in the prior section. In the following section the issue of PFPT morphology as a function of growth current density is more specifically addressed, in 
hope of discovering a morphological feature which would correlate to the differences observed.

\section{PFPT Morphology}

PFPT grown from a solution of $0.1 \mathrm{MFPT}$ in $1 \mathrm{M} \mathrm{TM} \Lambda \mathrm{T}$ in acctonitrile consist of a granular and rod-like structure. Figures 33,34 , and 35 show the morphology of deposited PFPT at $20 \mathrm{~m} \Lambda / \mathrm{cm}^{2}, 10 \mathrm{~mA} / \mathrm{cm}^{2}$, and $1 \mathrm{~mA} / \mathrm{cm}^{2}$, respectively. Each of these polymers represents an equivalent growth charge of $4 \mathrm{C}$. All photomicrographs depict a similar granular morphology. Figure 36 shows such a morphology at an increased magnification. It is therefore unreasonable to attribute the cyclic voltammetry differences incurred in Figure 32 to type of morphology acquired. However, there are differences in the amount and location of deposited polymer, as has been opinted out in the prior section.

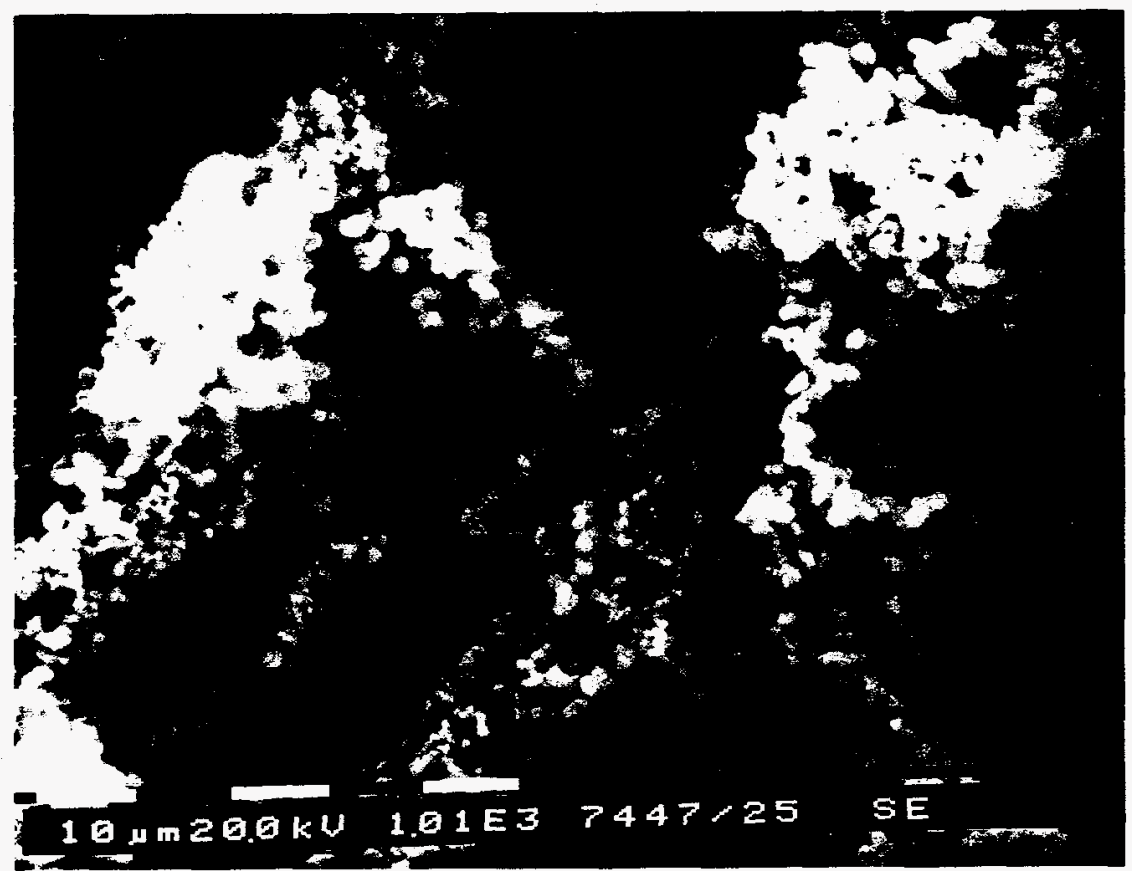

Fig. 33. Surface view of carbon electrode after polymer deposition at 20 $\mathrm{m} N \mathrm{~cm}^{2}$ for $200 \mathrm{~s}$ in $0.1 \mathrm{M} \mathrm{FPl}$ in $1 \mathrm{M} \mathrm{TMAT}$ in acetonitrilc. 


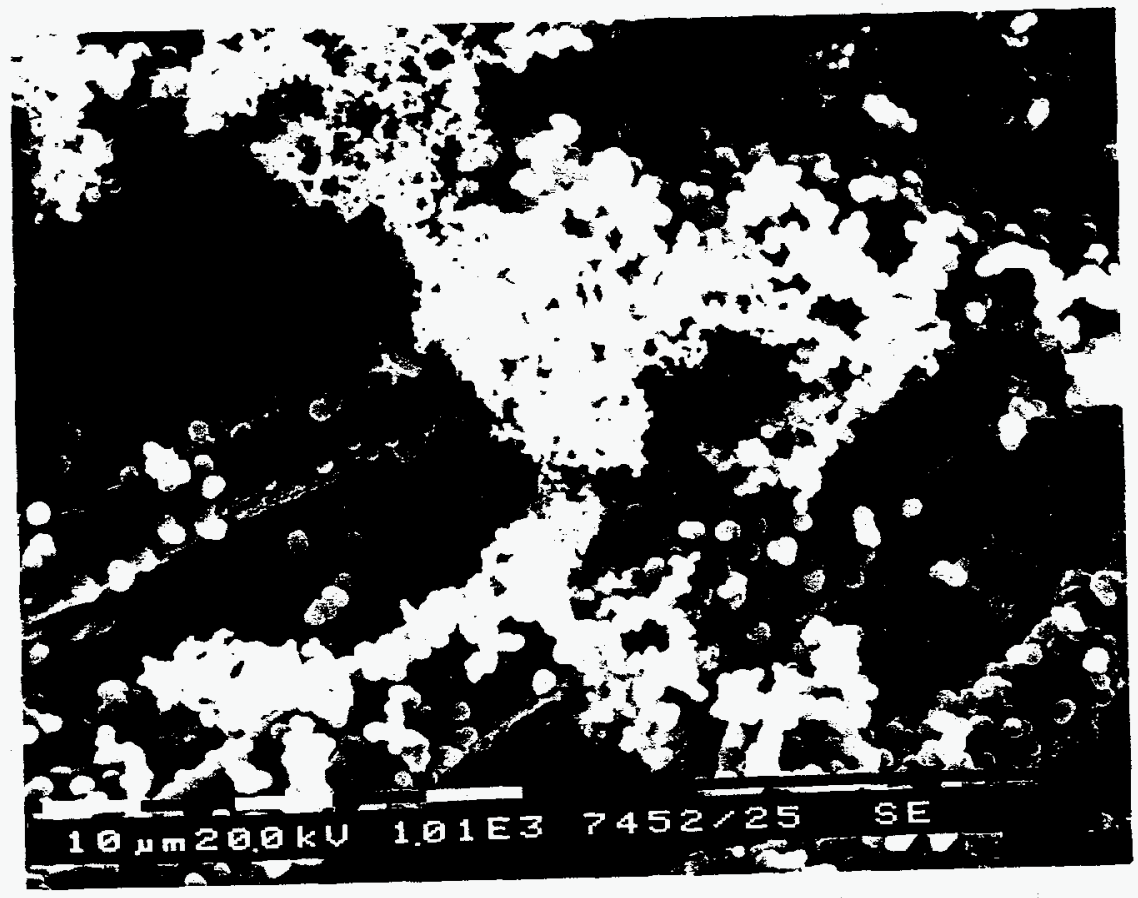

Fig. 34. Surface vicw of carbon electrode after polymer deposition at 10 $\mathrm{mA} / \mathrm{cm}^{2}$ for $400 \mathrm{~s}$ in $0.1 \mathrm{M} \mathrm{FPT}$ in $1 \mathrm{M} \mathrm{TMAT}$ in acetonitrile.

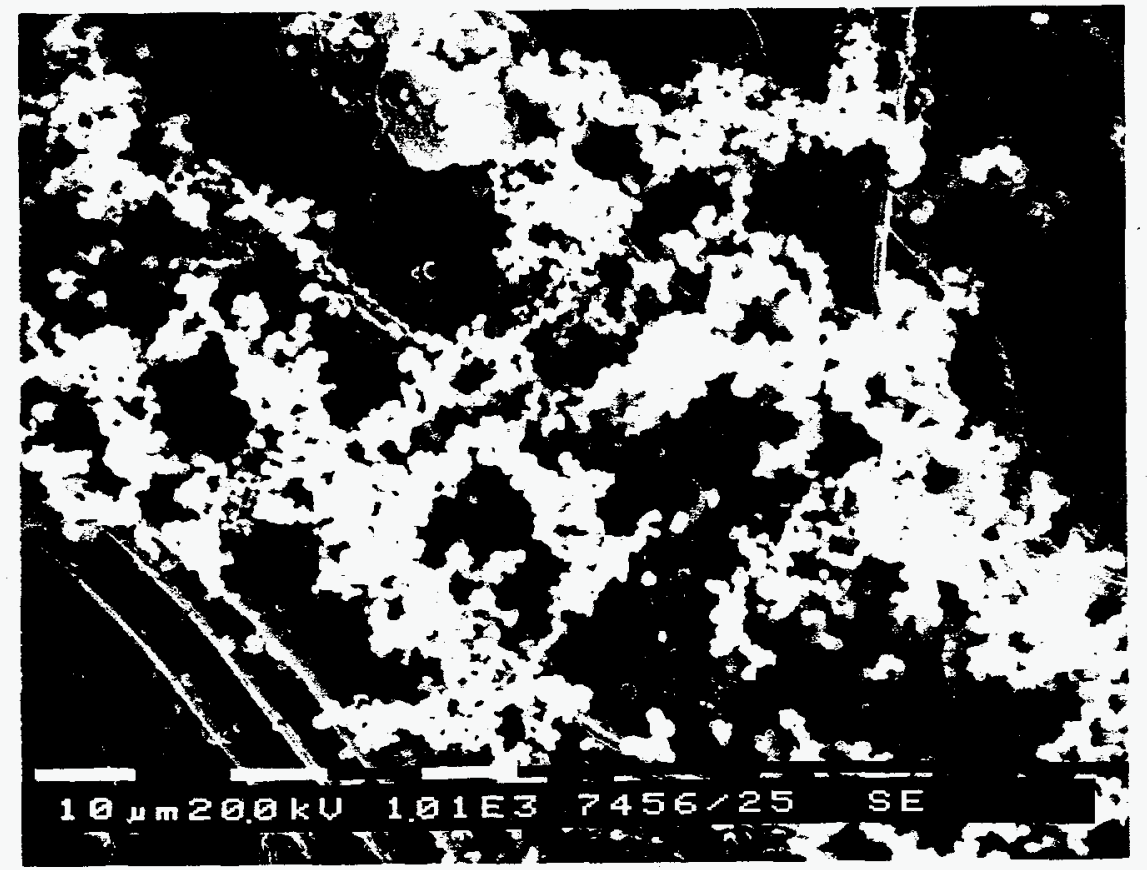

Fig. 35. Surface view of carbon electrode after polymer deposition at 1 $\mathrm{m} \Lambda / \mathrm{cm}^{2}$ for $4000 \mathrm{~s}$ in $0.1 \mathrm{M} \mathrm{FPT}$ in $1 \mathrm{M} \mathrm{TMAT}$ in acetonitrile. 


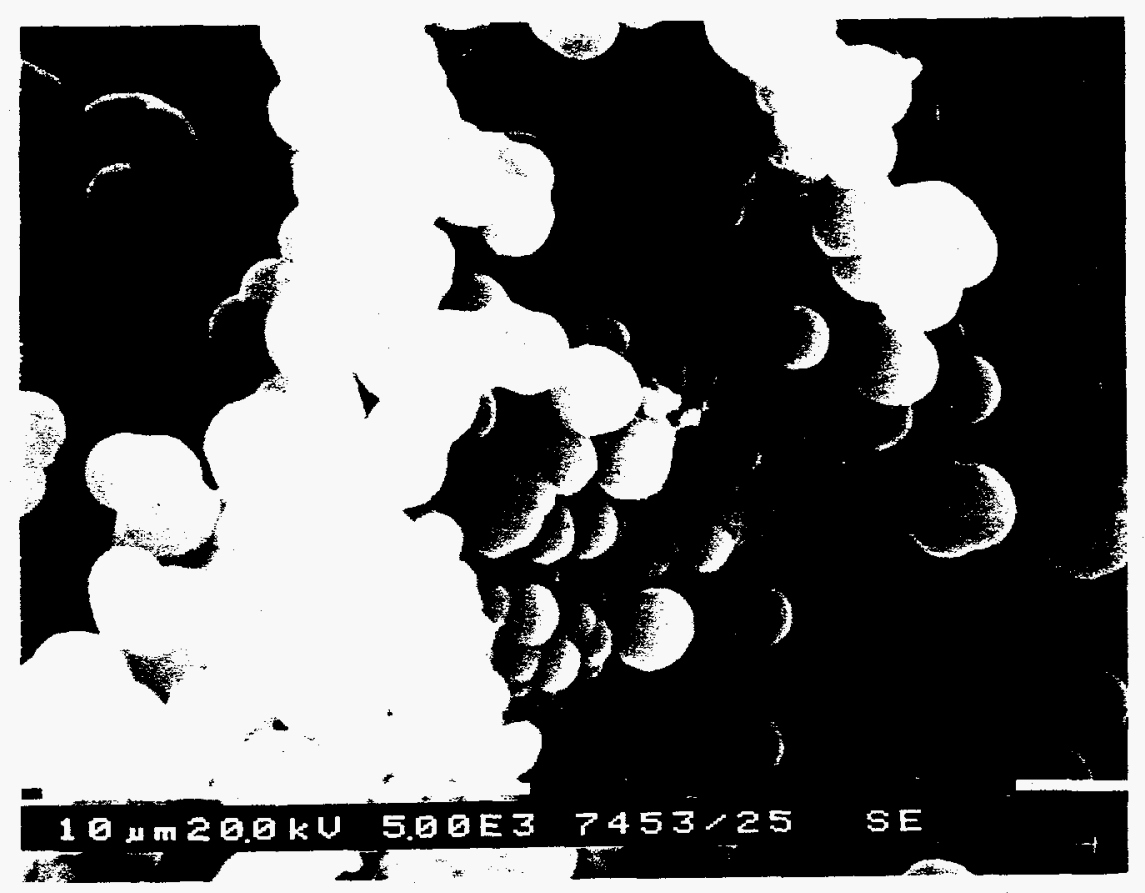

Fig. 36. Surface view of carbon clectrode after polymer deposition at 10 $\mathrm{m} N / \mathrm{cm}^{2}$ for $400 \mathrm{~s}$ in $0.1 \mathrm{MFP}$ in $1 \mathrm{M}$ TMAl in acctonitrile.

The cause of the differences in charge capacity (Figure 32) are most likely a result of an increased amount of polymer deposited at the higher current density, and/or a lack of electrode porosity. Pororsity here is meant to define the degree of continuous openness of the deposited networks. There is a considerable increase in the amount of polymer deposited on the outer electrode surface at $20 \mathrm{~mA} / \mathrm{cm}^{2}$, compared to an equivalent growth at $1 \mathrm{~mA} / \mathrm{cm}^{2}$. as shown in Figures 37 and 38. respectively. The formation of low molecular weight polymers. ligimers. at $1 \mathrm{~mA} / \mathrm{cm}^{2}$. which become soluble in the clectrolyte, may also explain the decrease in the amount ol polymer shown in Figure 38. Charge capacity differences may occur dic 10 an increase in the total amount of charge storage sites for the polymer grown all $20 \mathrm{~mA} / \mathrm{cm}^{2}$. 
As presented in Figures 28 through 30, a greater amount of polymer is deposited through the electrode thickness at $1 \mathrm{~mA} / \mathrm{cm}^{2}$ versus the higher current densities at equivalent growth charges. It was shown that at a current density of $20 \mathrm{~mA} / \mathrm{cm}^{2}$ there

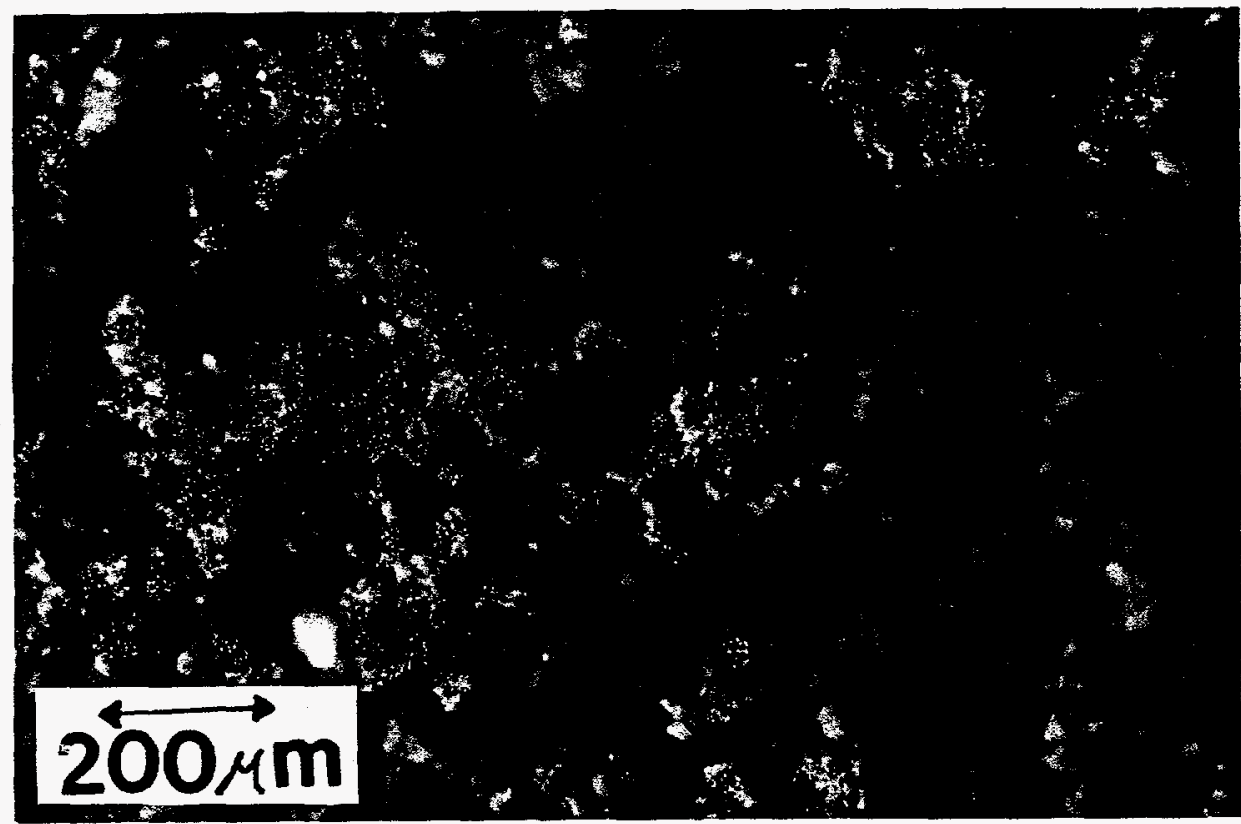

Fig. 37. Surface view of carbon electrode after polymer deposition at 20 $\mathrm{mA} / \mathrm{cm}^{2}$ for $1000 \mathrm{~s}$ in $0.1 \mathrm{M} \mathrm{FPT}$ in $1 \mathrm{MTMAT}$ in acctonitrile.

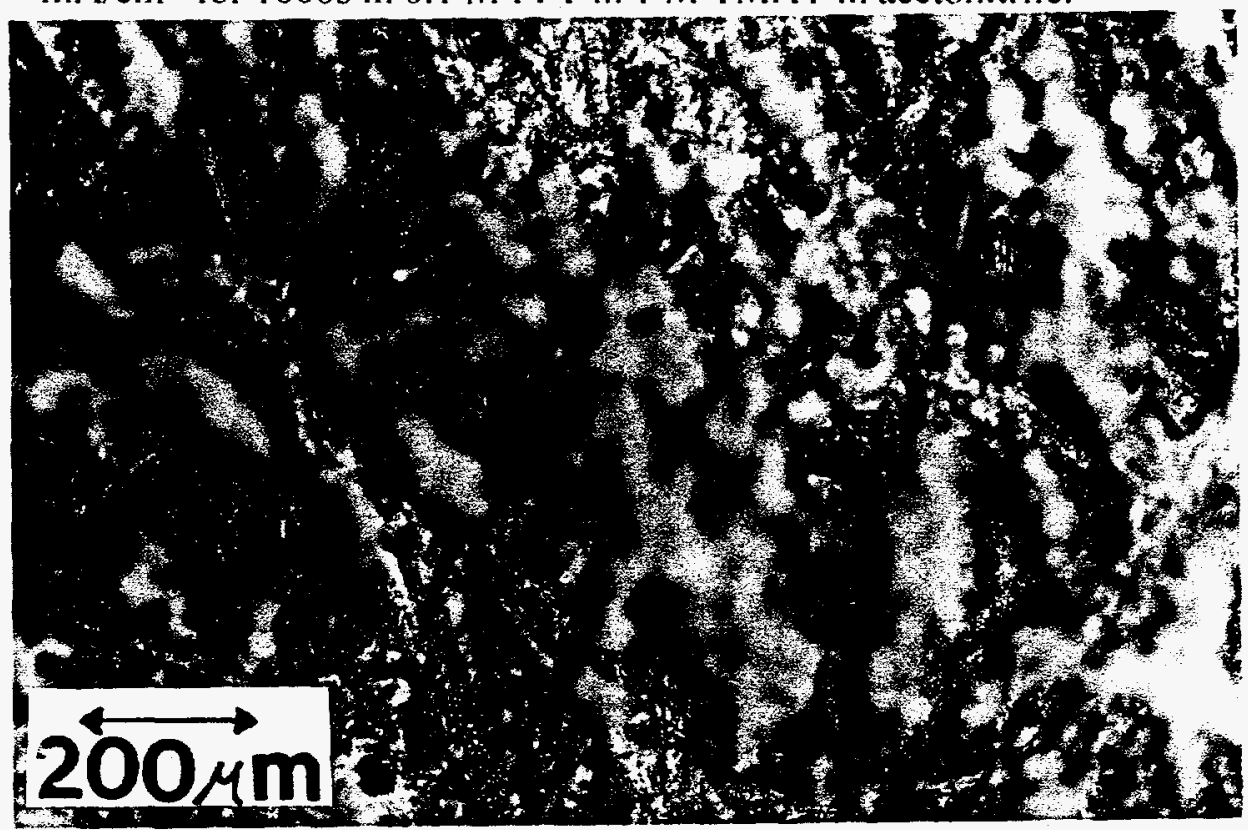

Fig. 38. Surface view of carbon electrode after polymer deposition at 1 $\mathrm{m} \wedge / \mathrm{cm}^{2}$ for $20000 \mathrm{~s}$ in $0.1 \mathrm{M} \mathrm{FPT}$ in $1 \mathrm{M}$ TMAT in acctonitrile. 
was a decrease in the amount of polymer deposited throughout the thickness of the electrode versus that of one deposited at $1 \mathrm{~mA} / \mathrm{cm}^{2}$. Such a feature, as described for the 1

$\mathrm{mA} / \mathrm{cm}^{2}$ deposited polymer, may result in "clogging" of the electrode, thus inhibiting electrolyte (ion) access to the in-thickness regions of polymer deposition. This could explain the observed decrease in the amount of stored charge at lower current densities, as shown in Fig. 32.

\section{Effect of Growth Electrolyte Concentration}

The effect of growth electrolyte concentration was considered in this experiment. The motivation behind this effort was to understand the role of electrolyte concentration on PFPT deposition. PFPT was deposited at $10 \mathrm{~mA} / \mathrm{cm}^{2}$ for $400 \mathrm{~s}$ and $1 \mathrm{~mA} / \mathrm{cm}^{2}$ for 4000s from a solution of 0.1 M FPT in 0.1 M TMAT in acetonitrile [the concentration of electrolyte for all polymer growth up to this point has been $1 \mathrm{M}$ solution of TMAT]. After polymer deposition the electrode was tested in a 1 M TMAT solution. The importance of a high ion salt concentration for electrochemical performance was presented in the section, Electrolytes.

Figure 39 shows the cyclic voltammograms for the polymer electrodes deposited at $10 \mathrm{~mA} / \mathrm{cm}^{2}$ and $1 \mathrm{~mA} / \mathrm{cm}^{2}$. Neither performed as well as the electrodes grown at equivalent current densities from a 1 M TMAT solution, as shown in Figure 32. The decrease in charge storage is most likely an effect of PFPT morphology. The morpholgy of PFPT deposited form an electrolyte of 0.1 M TMAT in acetonitrile (Fig. 40 and 41) is different from that deposited from a 1 M TMAT solution (see last section; Fig. 33 - 38). Differences in morphology are also observed as a function of growth current density. Figure 40 presents the morphology of a polymer deposited at $10 \mathrm{~mA} / \mathrm{cm}^{2}$ in $0.1 \mathrm{M}$ TMAT, and Figure 41 presents that of a polymer deposited at $1 \mathrm{~mA} / \mathrm{cm}^{2}$ in the same 
solution. The polymer deposited at $10 \mathrm{~mA} / \mathrm{cm}^{2}$ formed a clod-like sheath on the carbon fibers. The polymer deposited at $1 \mathrm{~mA} / \mathrm{cm}^{2}$ deposited as granules, similar to the morphology of that described in the prior section. Both polymers suffered in the amount of polymer deposited, which in turn directly affects the amount of stored charge in the electrode.

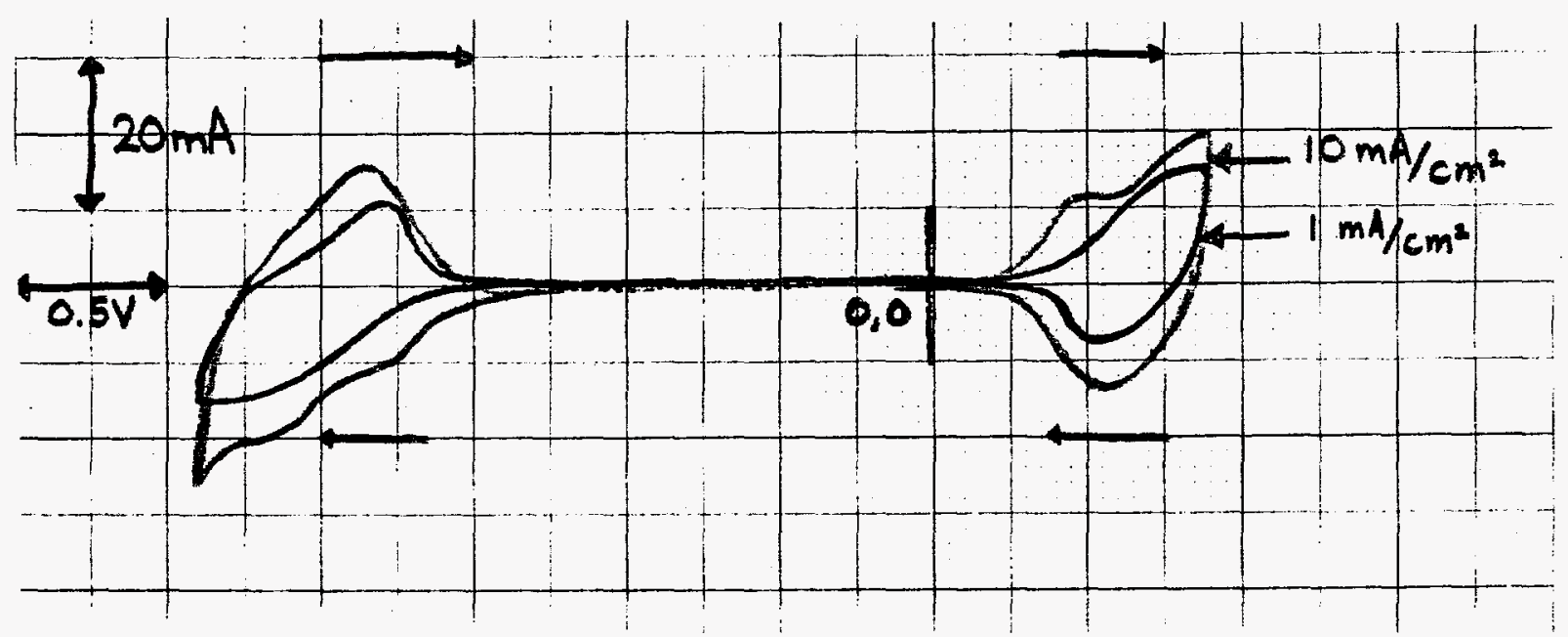

Fig. 39. Effect of growth electrolyte concentration on cyclic voltammetry.

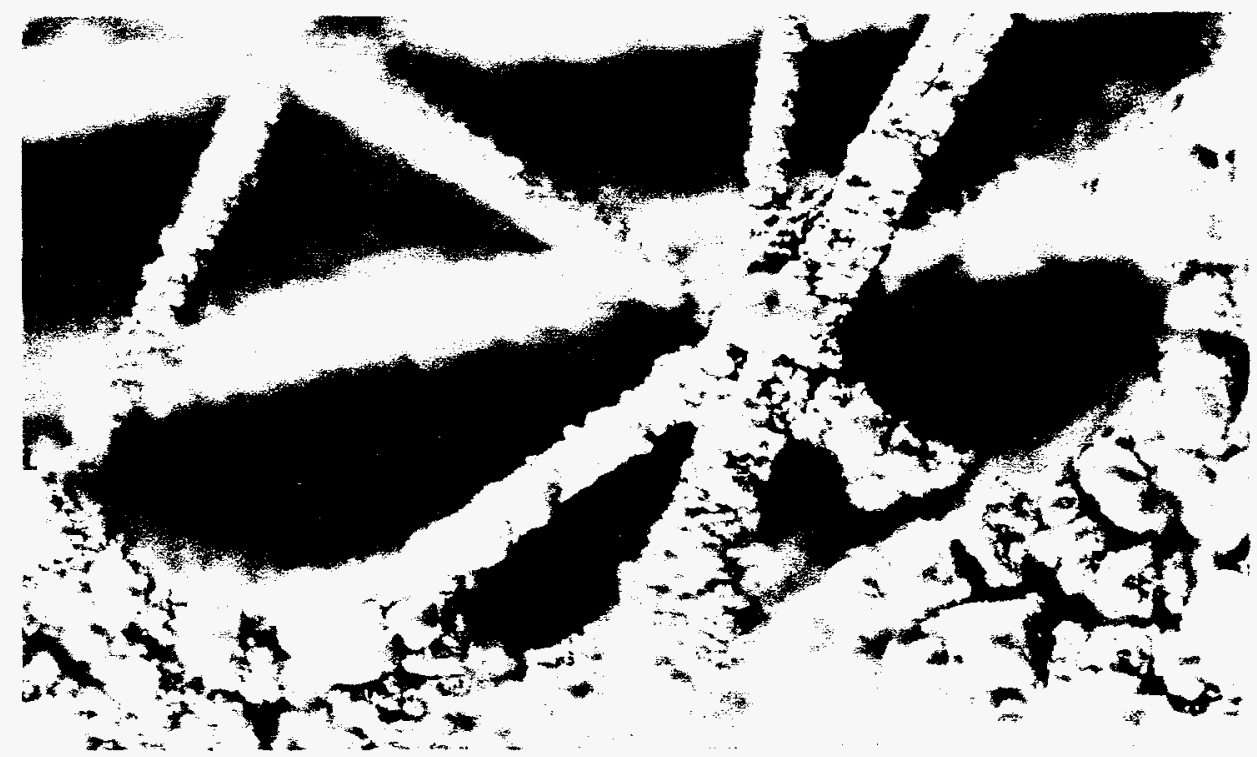

Fig. 40. Surface view of carbon clectrode after polymer deposition at 10 $\mathrm{m} \Lambda / \mathrm{cm}^{2}$ for $400 \mathrm{~s}$ in $0.1 \mathrm{M}$ FPT in $0.1 \mathrm{M}$ TMAT in acetonitrile. 


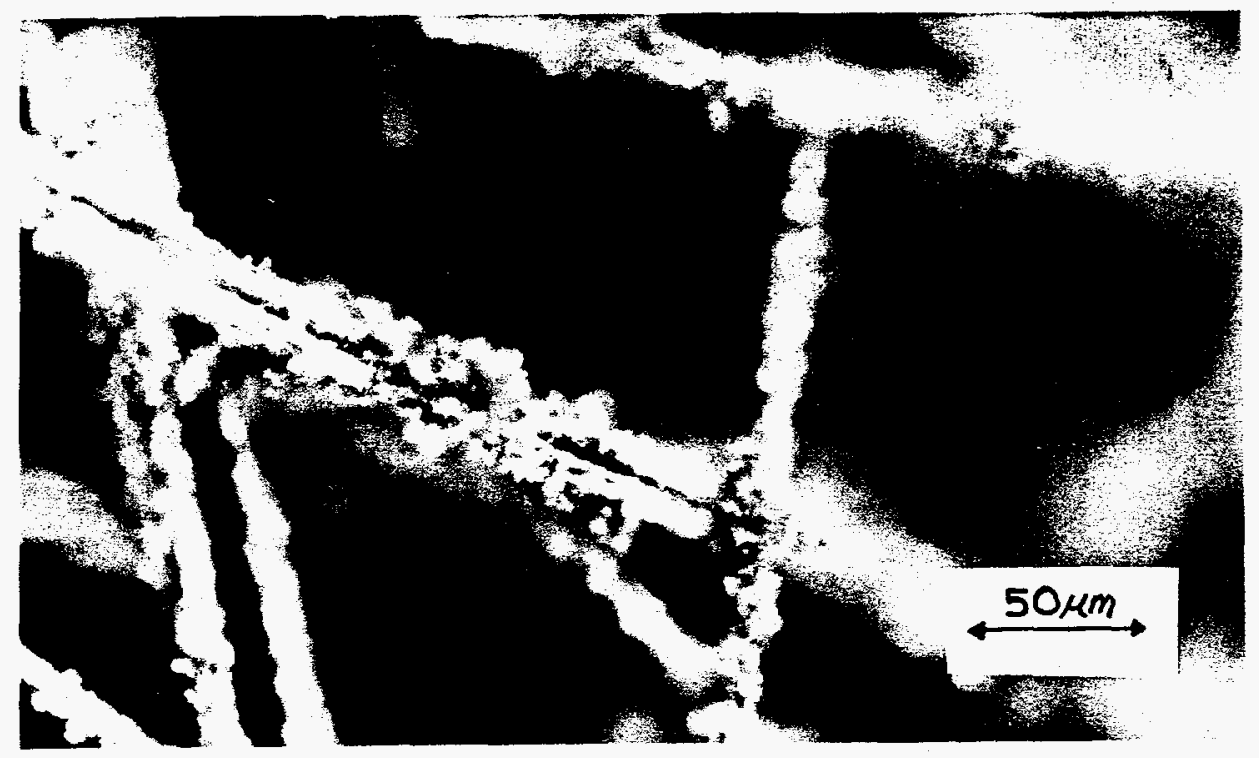

Fig. 41. Surface view of carbon electrode after polymer deposition at 1 $\mathrm{mA} / \mathrm{cm}^{2}$ for $4000 \mathrm{~s}$ in $0.1 \mathrm{M}$ FPT in $0.1 \mathrm{M}$ TMAT in acetonitrile.

\section{Cycle Dependent PFPT Degradation}

In order to acquire both p- and n-doping of PFPT it is required that the polymer be cycled between -2.4 volts and 0.9 volts. As the polymer is cycled through this extreme voltage window a number of times, a noticeable degradation of performance is observed in the resultant cyclic voltammograms. Figure 42 shows the effect of accumulated cycles on the degradation. PFPT was deposited at $20 \mathrm{~mA} / \mathrm{cm}^{2}$ for $1000 \mathrm{~s}$ and tested in a solution of $1 \mathrm{M}$ TMAT in acetonitrile. The 'green' curve shows both $\mathrm{p}$ - and $\mathrm{n}$-doping processes as the polymer is cycled between $-2.4 \mathrm{~V}$ and $0.9 \mathrm{~V}$. The 'red' curve shows just the p-doping of the polymer as it is cycled between $-1.5 \mathrm{~V}$ to $0.9 \mathrm{~V}$. Each successive line represents one full cycle between the voltage extremes. The 'green' curve undergoes a considerable performance degradation as the electrode is cycled. However, the electrode which was cycled only in the p-doping range (the 'red' curve) does not appear to suffer degradation.

Degradation may be a result of an irreversible redox reaction (a breakdown of the electrolyte) or possibly dissolution of the polymer into the electrolyte. The fact that the 
degradation occurs upon a combination of $\mathrm{p}$ - and n-doping, but not upon p-doping alone, narrows the possibilites. Electrolyte degradation or polymer dissolution is the result of the extreme low potential.

In an attempt to isolate the possibility of electrolyte degradation, a cell was set-up with a bare carbon working electrode in a solution of $1 \mathrm{M}$ TMAT in acetonitrile. Figure 43 shows the cyclic voltammogram of this experiment. The electrolyte undergoes no detectable degradation at the positive end of the applied voltage. However, at approximately $-2.0 \mathrm{~V}$ the electrolyte begins to accumulate charge, signifying its breakdown. Further solution analysis is required to determine if this electrolyte degradation is a result of the electrolysis of residue moisture, or if the acetonitrile itself is degrading.

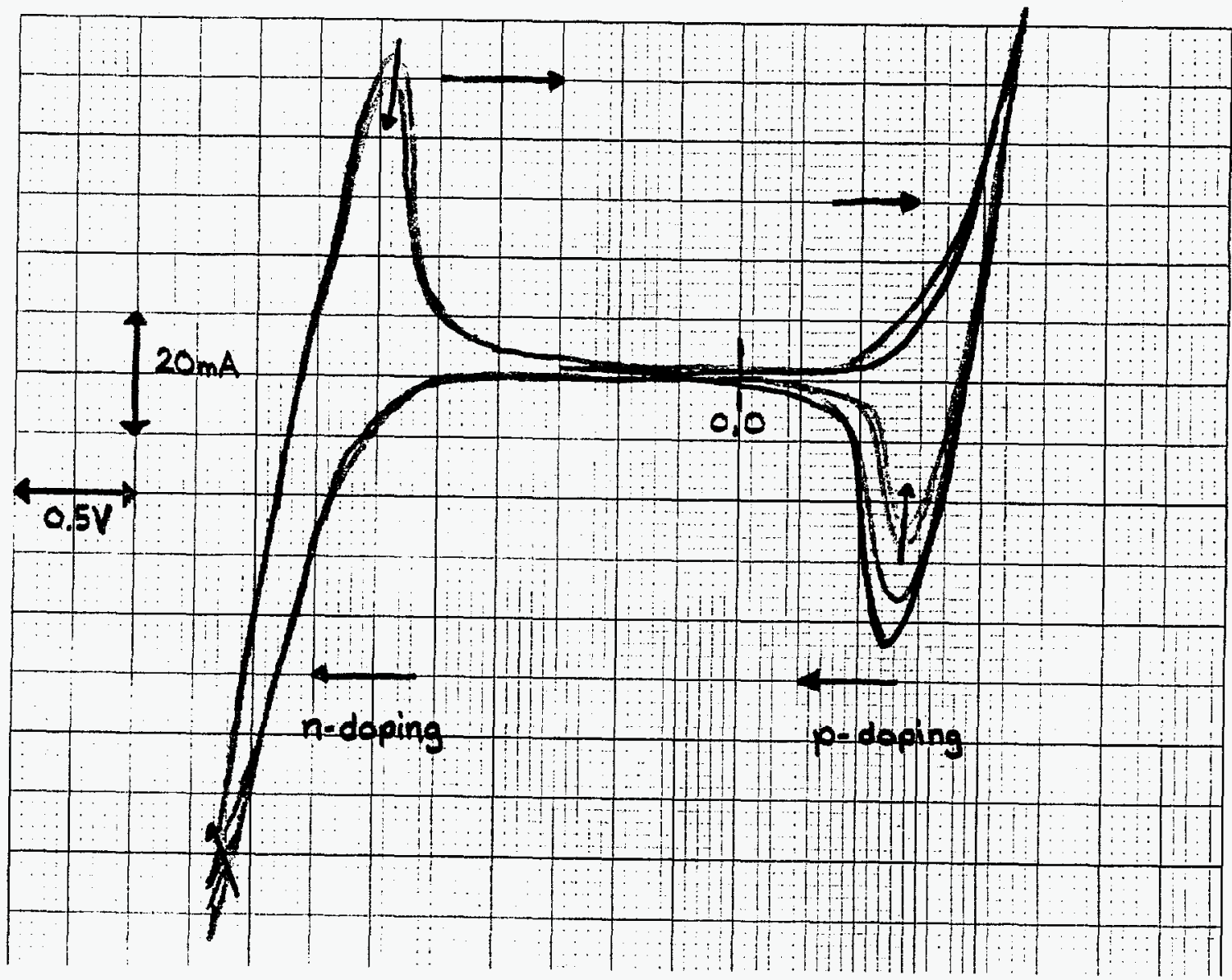

Fig. 42. Effect of degradation on cyclic voltammetry. 


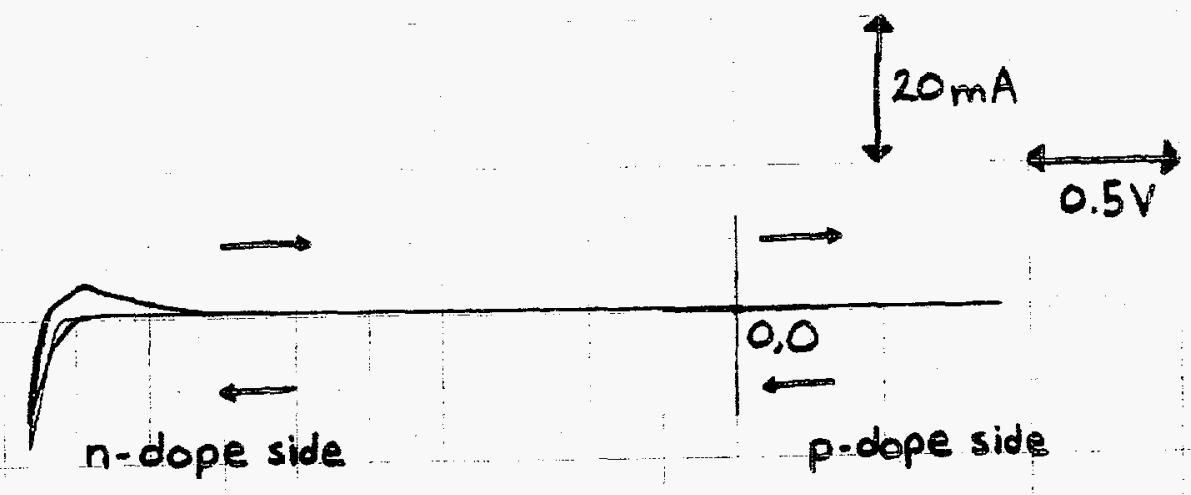

Fig. 43. Cyclic voltammogram of bare electrodes in $1 \mathrm{M}$ TMAT in acetonitrile.

The chemical redox reactions which occur at the anode versus the cathode are necessarily different. The argument for polymer dissolution may be supported by scanning electron and optical microscopy. Figurc 44 shows a PFPT film after it has been cycled through $\mathrm{p}$ - and $\mathrm{n}$-doping processes. The morphology, as described in preceding sections, is granular. Ilowever, there arc clusters of granules (area A) that are considerably smaller in size than the rest. This may be evidence of polymer dissolution, or it may simply be a consequence of the initial growth conditions. Because as-deposited specimens were not examined to varify or deny the existance of this binodal distribution of grain sizes, further analysis is required before any viable conclusions on the different degradation mechanisms at the anode and cathode can be given.

Figure 45 shows regions of polymer which are black in color and regions which are bright orange. These color differences may reflect degradation regions, either due to an irreversible redox reactions or polymer dissolution. In relation to conducting polymer use in clectrochromic devices, PFPT will change color as it is charged (doped). Therefore, the photomicrograph presented in Figure 45 may reflect the areas that are not doped (black regions) and areas that are (orange regions). A second theory is that the granules that form during deposition dissolve into the electrolyte during degredation, resulting in a 
granule smaller than $1 \mu \mathrm{m}$ in diameter, as shown in Figure 44 . This falls just within the spectrum for interaction (selective absorption) with the visible light spectrum. Granules may effectively absorb visible light and thus they appear black in the photomicrograph. Other granules of different size may only partially absorb visible light: and thus, they appear orange. This observation suggests that polymer dissolution may therefore be evaluated with an optical microscope. A light-pipe built into the deposition/testing cell may be most useful.

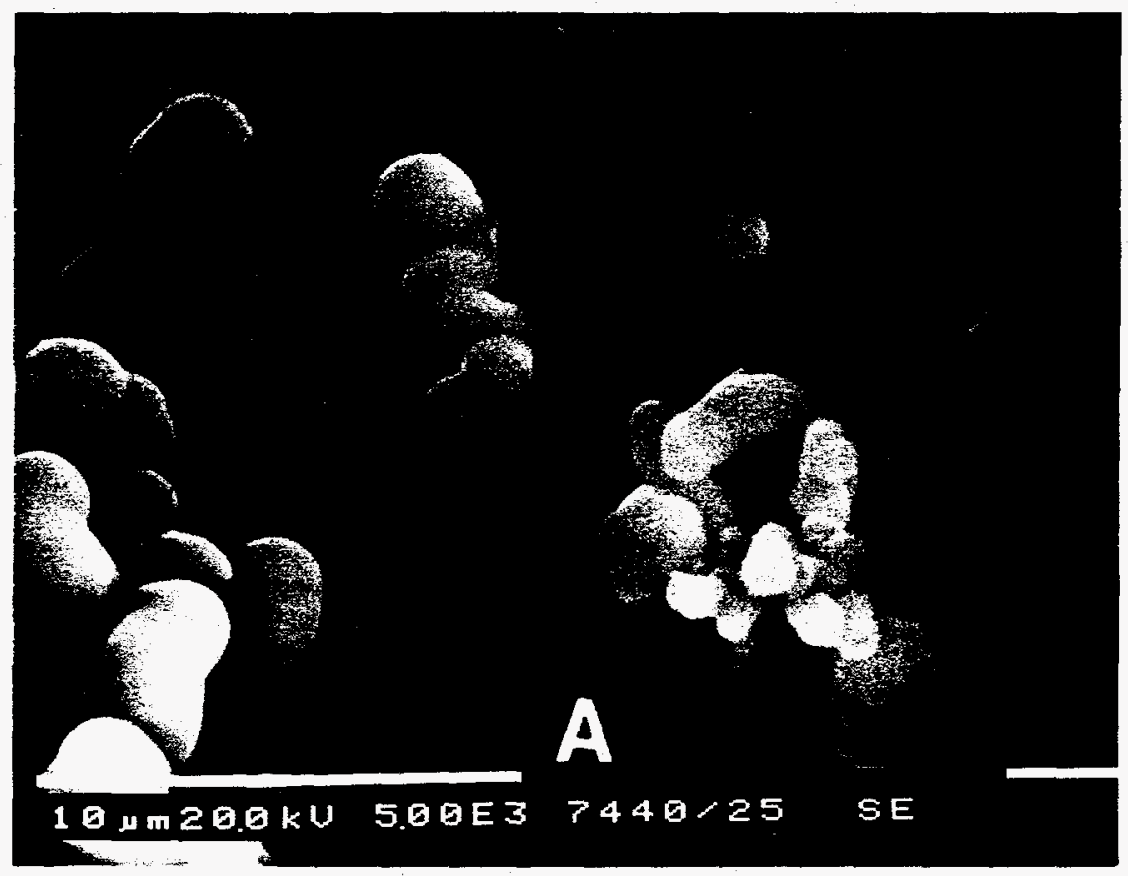

Fig. 44. Surface view of carbon electrode after polymer deposition (and cycled) at $10 \mathrm{~mA} / \mathrm{cm}^{2}$ for $2000 \mathrm{~s}$ in $0.1 \mathrm{M} \mathrm{FPT}$ in $1 \mathrm{M}$ TMAT in acetonitrilc. 


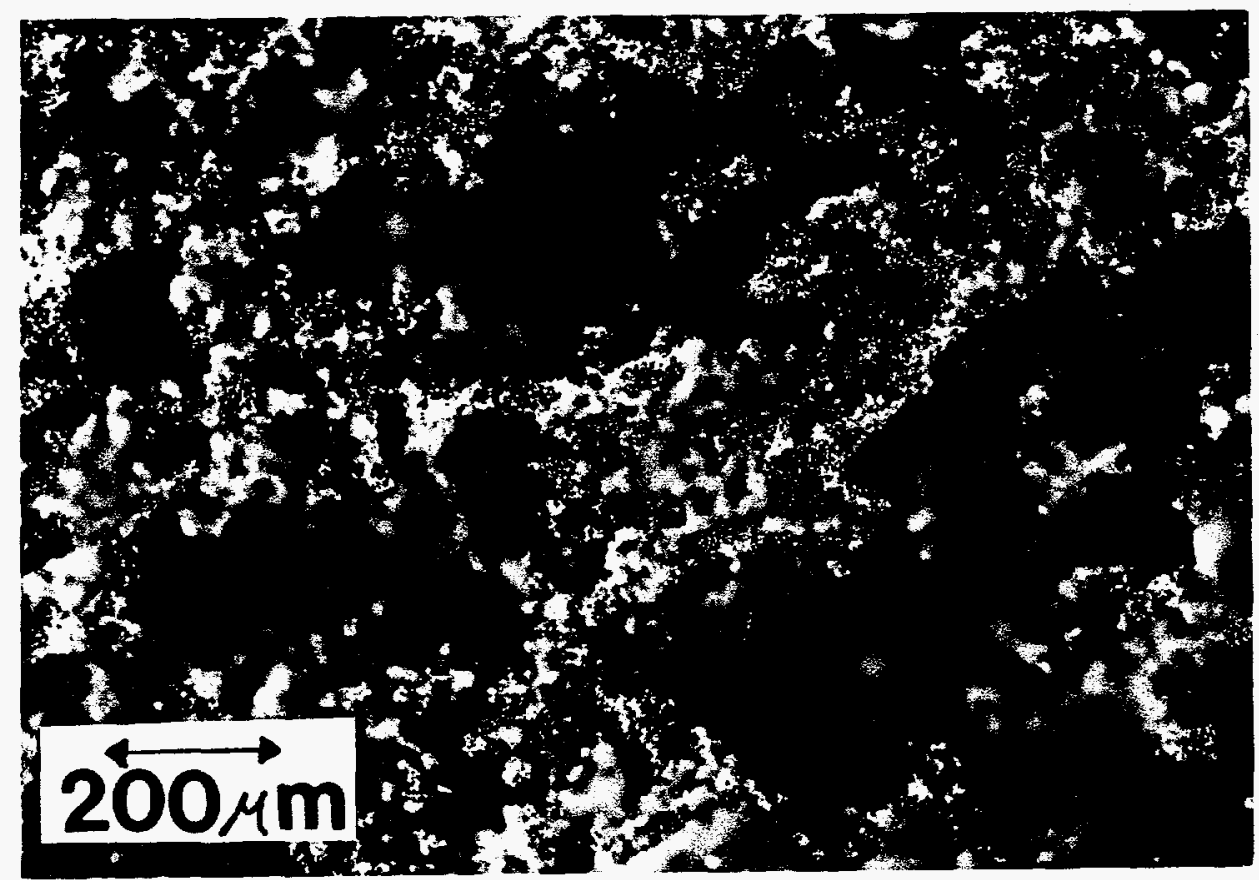

Fig. 45. Optical photomicrograph of surface view of carbon electrode after polymer deposition (and cycled) at $10 \mathrm{~mA} / \mathrm{cm}^{2}$ for $2000 \mathrm{~s}$ in $0.1 \mathrm{M}$ FPT in 1 $M$ TMAT in acetonitrile. 


\section{Conclusions}

\section{Polvaniline (PAni)}

Scanning electron microscopy has revealed that the morphology of electrochemically grown polyaniline is strongly dependent on growth conditions. PAni grown at $1 \mathrm{~mA} / \mathrm{cm}^{2}$ has a granular morphology. When PAni is grown at $10 \mathrm{~mA} / \mathrm{cm}^{2}$, the morphology of the resulting polymer film consists of a network of spherical (or rod-like) building blocks. The exact nature of these building blocks is strongly dependent on growth conditions. Morphology consistent with required performance characteristics of electrochemical capacitors is obtained at higher growth currents. At these high currents, the polymer morphology is independent of the substrate structure. The utilization of a planar substrate will reduce the overall weight of the electrode.

\section{Poly-3-(4-fluorophenyl)-thiophene (PFPT)}

PFPT films deposited at $20 \mathrm{~mA} / \mathrm{cm}^{2}$ resulte in higher charge capacity than those deposited at lower current density. This is most likely a result of more PFPT polymer being deposited on the outside of the porous electrode substrate in direct contact with the electrolyte. The fact that more polymer is deposited throughout the thickness of an electrode at $1 \mathrm{~mA} / \mathrm{cm}^{2}$ leads to a depletion of ions within the carbon fiber electrode and this reduces the overall electrochemical performance. Monitoring the potential during constant current oxidation does provide information on the growth morphology from a potential vs. time trend curve. Regions of through-thickness deposition, monomer depletion, and polymer conductivity can be distinguished. Degradation of the electrolyte/electrode is observed as the electrode is cycled between oxidation and reduction reactions, but not when it is solely cycled between oxidation reactions. The binodal formation of smaller granules is believed to be attributed to this degradation as well. 


\section{Future Directions}

It is suggested that future efforts on this project emphasize the source of binodal distribution of granules, whether they are a result of the deposition or dissolution. The degradation reactions which seemingly differ at the anode and cathode, and the use of mass spectroscopy to determine the possible formation of low molecular weight polymers, should be researched further. The role of optical photomicroscopy as an analytical tool should be emphasized further, especially in the area of determining the cause of color variations of the polymer. 


\section{References}

[1] Raistrick, 1., Electrochemical Capacitors, Electrochemistry of Semiconductors and Electronics-Processes and Devices, Nayes, New Jersey, Chapter 7(1992), 297-356.

[2] Rudge, A., Davey, J., Raistrick, I., Gottesfield, S., and Ferraris, J., Conducting Polymers as Active Materials in Electrochemical Capacitors, (Submitted to Electrochimica ACTA).

[3] McCosh, D., We Drive the World's Best Electric Car, Popular Science, (Jan.1994), 52-58.

[4] Faulkner, L., Understanding Electrochemistry: Some Distinctive Concepts, Journal of Chemical Education, 60(1983), $262-264$.

[5] Naegle, D., Polypyrrole Supercapacitors, Electronic Properties of Conjugated Plymers II, Springer-Venberg Berlin, $91,1989$.

[6] Heinz, J., Electrochemistry of Conducting Polymers, Synthetic Metals, 41-43(1991), 2805-2823.

[7] Diaz, A., Castillo, J., Logan and Wen-Yaung Lee, Electrochemistry of Conducting Polypyrnole Films, J. Electroanal. Chem., 129(1981), 115-132.

[8] Naoi, K., Lien, M., Smryl, W., and Owens, B., Capacitive Behavior in Conducting.Polymers, Applied Physics Communicatoins, 9(1989), 147-162.

[9] Conway, B., Iransition from "Supercapacitor" to "Batterv" Behavior in Electrochemical Energy Storage, J. Electrochem. Soc., 138(1991), $1539-1548$.

[10] Taguchi, S. and Tanaka, T., Eibrous Polyaniline as Positive Active Material in Lithium Secondary Batteries, Journal of Power Resources, 20(1987), 249-252.

[11] Evans, D., O'Connell, K., Peterson, R., and Kelly, M., Cyclic Voltammetry, Journal of Chemical Education, 60(1983), $290-292$.

[12] Kroschwitz, J.I., Electical and Electronic Properties of Polvmers, John Wiley \& Sons, 1988.

[13] Cotts, D.B., and Reyes, Z., Electrically Conductive Organic Plymers for Advanced Applications, Noyes Data Corporation, New Jersey, 1986.

[14] Skotheim, T.A., Handbook of Conducting Polymers, Vol. 1, Marcel Dekker, New York, 1986.

[15] Bredas, J., Themans, B., Fripat, J., Andre, J., Chance, R., Synthetic Metals, 9:265 (1984).

[16] Hotta, S., Hosaka, T., and Shimotsuma, W., Synthetic Metals, 6:317 (1983).

[17] Air Resources Board, Califormia Code of Regulations Title 13, Section 1960.1. 